\title{
INTERROGATING PSYCHOCENTRISM AND THE ROLE OF A WHITE \\ RESEARCHER
}

\author{
by \\ Jordana Rovet, BSW, Ryerson University, 2015
}

\begin{abstract}
An MRP
presented to Ryerson University
\end{abstract}

in partial fulfillment of the

requirements for the degree of

Master of Social Work

in the Program of

Social Work

Toronto, Ontario, Canada, 2017

(C) Jordana Rovet 2017 


\section{AUTHOR'S DECLARATION FOR ELECTRONIC SUBMISSION OF A MRP}

I hereby declare that I am the sole author of this MRP. This is a true copy of the MRP, including any required final revisions.

I authorize Ryerson University to lend this MRP to other institutions or individuals for the purpose of scholarly research.

I further authorize Ryerson University to reproduce this MRP by photocopying or by other means, in total or in part, at the request of other institutions or individuals for the purpose of scholarly research.

I understand that my MRP may be made electronically available to the public. 


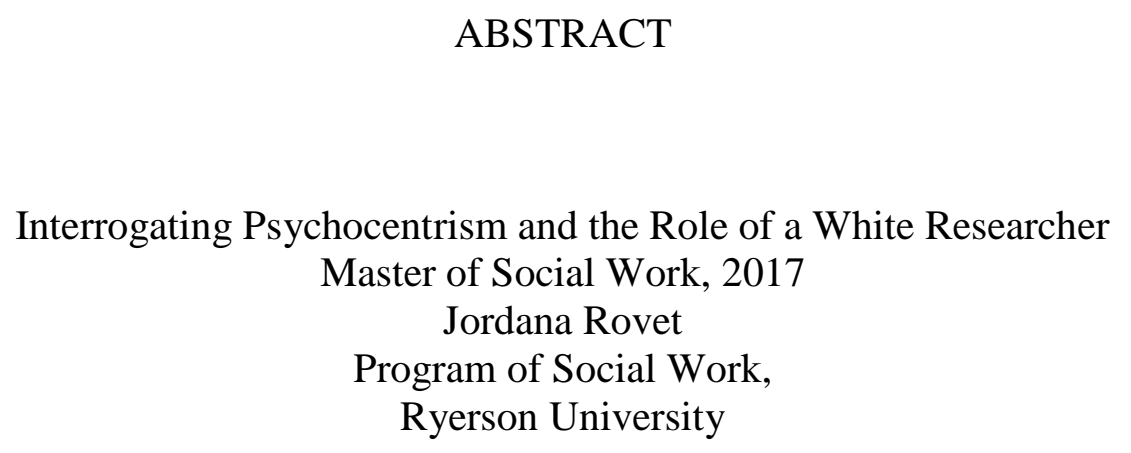

This work represents a culmination of experiences of individuals who have been subjected to adolescent psychiatrization and particularly, the influences of psychocentrism. This work builds upon the notion of psychocentrism as a social justice issue by exploring how its' embeddedness within dominant mental health discourse functions to disregard the systemic, historical and cultural factors contributing to individual experiences of emotional distress. Through this analysis, the tensions of a white researcher with social justice aims is problematized and explored in tandem with the findings of this research. 


\section{ACKNOWLEDGEMENTS}

There are so many people who deserve to be acknowledged for their influence on this work. I would first like to express a sincere thank you to Cassandra, Bailey and Jane who so graciously agreed to participate in this research. I would not have been able to complete this work had it not been for your invaluable contribution. To my MRP supervisor, Gordon Pon, I would like to thank you for your ongoing support, encouragement and guidance throughout this research process. Your supervision allowed for me to develop a deeper understanding and respect for the research process, as well as, myself as a researcher. To my professors, Idil Abdilahi, Cyndy Baskin, Lynn Lavallée, Kristin Smith and Notisha Massaquoi, I would like to thank you for continuously encouraging me to challenge my thinking and critically engage in self-reflexivity. I would also like to acknowledge Jennifer Poole, the graduate program director, who continuously reminded me that her door was always open to offer support when I needed it. Lastly, but most importantly, I would like to acknowledge my colleagues in the 2016-2017 MSW cohort. The majority of my learning this year has undeniably come from my colleagues who consistently took on the emotional labor of telling me when I was wrong, spoken out of place, apologized too quickly or engaged in white flight or fragility. It is my peers who held me accountable for my actions and I could not be more grateful to those who continuously took on this burden. This MRP represents a reflection of many of the teachings my colleagues have provided me and if it were not for them, this work would not have been possible. 


\section{DEDICATION}

This work is dedicated, first and foremost, to myself and the self who never expected I would arrive at this juncture in my life. This work is also dedicated to my parents for their unconditional love and support. Without them, I would not have been able to achieve such an accomplishment. 


\section{TABLE OF CONTENTS}

Chapter 1: INTRODUCTION

Chapter 2: LITERATURE REVIEW

Chapter 3: THEORETICAL FRAMEWORK

Chapter 4: METHODOLOGY

Chapter 5: FINDINGS \& ANALYSIS

Chapter 6: DISCUSSION

Chapter 7: IMPLICATIONS

Chapter 8: CONCLUSION

Appendices

Reference List

Glossary
Page \# 1

Page \# 4

Page \# 17

Page \# 24

Page \# 29

Page \# 44

Page \# 48

Page \# 53

Page \# 54

Page \# 59

Page \# 67 


\section{LIST OF APPENDICES}

Appendix A - INTERVIEW GUIDE

Appendix B - RECRUITMENT TRANSCRIPT

Appendix C - CONSENT FORM
Page \# 54

Page \# 55

Page \# 56 


\section{CHAPTER 1. INTRODUCTION}

My original title for this research project was Psychiatry Leaving a Question Mark. My intention was to explore and interrogate the psychiatric system by uncovering individual stories of madness and survival. This objective was motivated by a strong desire to trouble and deconstruct the system which I myself was subjected to as an adolescent. I intentionally use the words ‘subjected to' because I, like many, were not given the agency or autonomy to decide for ourselves whether we wished to come into contact with the mental health system. However, this research is nothing that I thought it would be, and everything that it originally was not. It represents a story of a researcher becoming the researched, through a lens never intended. It is a messy culmination of psychocentric analysis and an interrogation of myself as a white researcher, as well as, the tensions of conducting research with social justice goals. In embarking on this research, I recognize that my understanding of this subject is influenced by multiple aspects of my identity. As someone who has experienced the mental health system as an adolescent, I am biased by my own experiences and thus, my desire to explore experiences of madness are intertwined with my own desires to 'recover' from my own experiences. The selfinterest which guided my research focus, persisted throughout the development of this research design. This research in no way aims to be objective. I intentionally point this out because it is my hope that you will read this paper with the understanding that I am situated throughout this research. As a white woman of privilege, my position in relation to this work means everything. As a white woman attempting to research intersectional experiences of madness, I was constantly reminded of these categories that I visibly occupy. My ability and confidence in challenging psychiatry, mental health and madness is oriented within my whiteness and as I persisted with my research, this reality became increasingly more apparent. As a social work practitioner, I also 
recognize that even when standing in opposition to processes of colonialism, racism and psychocentrism, I am acutely aware of my own complicity in that which I am critiquing. Therefore, like Fanon (1968), "I have not wished to be objective. Besides that would be dishonest, it is not possible for me to be objective.” As I am writing, I am writing myself into the problem and struggling with the ways that we are "inscribed in that which we struggle against" (Lather, 1991).

This research will explore the impact of adolescent mental health experiences or as I will refer to experiences of madness or emotional distress. This work will use the terms experiences of madness and emotional distress interchangeably as opposed to 'mental illness' in an effort to avoid the false implication that there is scientific proof or medical consensus of psychocentrism. Psychocentrism is itself a form of social injustice, where individual reformation is promoted rather than social and economic justice. Thus, emotional distress, in this work, is to be understood as a by-product of societies built on systemic inequalities that produce social injustices (Rimke, 2016). To challenge biomedical explanations of emotional distress, psychiatric consumers and survivors have coined the 'Mad' identity in resistance to the identities imposed upon them by the 'psy-complex' (Lefrancois, Menzies, Reaume, 2013). The 'psycomplex’ entails a loosely defined group of experts, such as psychologists and psychiatrists, connected through their professional status who take up practices which produce, legitimize and utilize psychiatric discourse (Rimke, 2016). The 'psy-complex' will be problematized in this work by applying the notion of 'psychocentrism'. The term psychocentrism has been coined by Rimke (1997) to describe the narrow, limited and uni-focused view of mental health whereby pathologies are seen to be based in the mind and/or body of the individual. Psychocentricity encompasses ten guiding principles; reductionism, determinism, essentialism, presentism, 
naturalism, ethnocentrism, double standards, victim blaming, positivism and pathological individualism (Rimke, 2016). Psychocentrism legitimizes the pathologization, marginalization and oppression of 'Mad' individuals as well as the subjugation of Mad knowledges. In recognizing the increasing hegemony of psychiatric discourse, this research will utilize the concept of psychocentrism to investigate the ways in which 'psy' knowledge governs and regulates social conceptions of normalcy through biomedical explanations for emotional distress.

Supplementary to that, I wondered about the use of psychocentric determinism to justify a system that is actively oppressing racialized communities. To insist that emotional distress is determined by biological characteristics is to imply that emotional distress is devoid of external, social or historical factors. This already positions racialized communities as more susceptible to be pathologized as experiences of collective trauma are ignored within a psychocentric perspective. If particular types of bodies are more susceptible to be seen as 'deviating' from the norm and thus, more susceptible to be pathologized, then psychocentrism is arguably an active system perpetuating white supremacy. White supremacy, in this work, does not refer to neo-Nazi type groups who perpetrate acts of violence against minority groups (although this is also a feature of such a regime), rather it refers to a hegemonic social system which normalises the disadvantage of ethnic minorities and the privilege of white people by influencing attitudes, policy and interaction (Chadderton, 2012). Thus, this work will challenge the modern liberal view of racism as conscious, deliberate and visible by focusing on the often covert ways in which white supremacy functions to maintain the status quo. This work will also build upon notions that psychocentrism is a social justice issue by taking it one step further and exploring how psychocentrism is connected to ongoing colonial relationships and the maintenance of white supremacy. 


\section{CHAPTER 2. LITERATURE REVIEW}

There is an overwhelming amount of research conducted on experiences of adolescent psychiatry, yet it is quite difficult to find research which stems from an epistemological lens other than positivism. This demonstrates the dominance of psychocentricity within science and scientific enquiry. A positivist epistemology assumes that there is only one reality and that science is the only foundation for true knowledge (Chilisa, 2012). Therefore, positivism not only subjugates other forms of knowledge, but is inherently exclusionary of them. As the literature was explored, it was soon realized that the amount of empirical research studies on this topic extends far beyond the capacities of this initiative. Thus, the studies chosen for this literature review were purposefully selected based on their focus on the lived experiences of psychiatrization and their connection to the sociopolitical context within which psychiatry is based. The following literature review represents a summary of scholarly findings, identifying three central themes related to this study; the internalization of pathological discourse, ability to participate in healthcare decisions and experiences of intersectional oppression amongst individuals involved with the mental health system.

\section{Pathologization}

Many studies have shown that adolescents today are more likely to be given a psychiatric diagnosis than ever before (Olfsen, Blanco, Liu, Moreno, \& Laje, 2006). The undue pathologization of adolescent behavior is evident amongst the literature. In a study conducted on the effects of self-labeling among adolescents, participants demonstrated a strong likelihood to question the pathologization of their experiences and wonder if their behavior falls within the range of 'normalcy' or if it reckons the label of 'disordered' (Moses, 2009). This idea reoccurs in a study conducted in Canada whereby adolescents similarly reported uncertainty as to whether 
their problems could be understood as "just a normal bad period in their lives" or had become something more serious (Bluhm, Covin, Chow, Wrath \& Osuch, 2014). The tendency for adolescents to compare their experience of depression with normal sadness is repeatedly mentioned throughout the literature. This realization prompted the question; is it possible to experience poor mental health without being considered 'disordered' within a psychocentric perspective?

In a study conducted on self-labeling and its effects amongst adolescents diagnosed with mental health disorders, participants further evidenced ambivalence in responding to questions about their views of their diagnosis and consistently resorted to non-pathological explanations for their emotional distress (Moses, 2009). The tendency for adolescents to reject pathological explanations for their behavior is echoed in a study which explored teens' efforts to understand their depressive experiences (Wisdom \& Green, 2004). Interviews with high school students who had been diagnosed with depression, evidenced the continuous explanation for their behavior as being caused by significant external events, including parental divorce, a family member experiencing cancer treatment, child abuse, problems with friends and death of a relative (Bluhm et al., 2014; Wisdom \& Green, 2004). Notwithstanding the purpose of their research, scholars still resort to psychiatric discourse to discuss their findings. Relying on psychiatric discourse to discuss experiences within the mental health system does nothing to uncover the injustices being done to them and serves only to reinforce experiences of sanism. The term sanism was coined in the 1960’s by attorney Mortin Birnbaum (Birnbaum, 1960) and popularized by Michael Perlin (Perlin, 1993), to describe "the belief system that makes it normal to pick on, make fun of, discriminate, reject, silence, incarcerate, shoot at and commit other forms of violence against people who are othered through mental ‘illness’ diagnosis, opinion, and experience” (Abdillahi, 
Meerai \& Poole, 2017, p. 5).

The incorporation of psychiatric discourse into one's self-perception or what is more commonly termed 'self-stigma' is another factor discussed amongst the literature. In a study conducted on the effects of self-labeling, Moses (2009) interviewed adolescents about the extent to which they identified with their psychiatric disorder and the impact self-labeling has had on their psychological well-being. This study found that adolescents who self-label using psychiatric discourse report higher ratings on self-stigma and depression than those who do not (Moses, 2009).

The power dynamics evident in the patient-psychiatrist relationship further renders adolescents vulnerable to adopt diagnostic language to describe their experiences. Wisdom and Green (2004) further explored the tendency for adolescents to accept physician's explanations for their experiences despite internal conflict,

It was a little bit of a shock [when my physician diagnosed me with depression] because I just figured I was just being sad like any other kid but I didn’t know it was that bad that I had depression and all that stuff and I needed to go on medication (p. 1234). This tendency is worrisome because adolescents who adopt the diagnostic labels provided to them by psychiatric professionals are found to be more pessimistic about the likelihood of recovery and tended to view interventions with suspicion and hopelessness (Wisdom \& Green, 2004). Wisdom and Green (2004) urge medical providers and parents to consider how individual teens respond to a diagnosis; whether they find it a useful label, medicalize the situation or incorporate the diagnosis into part of their identity. Their findings suggest that for many, diagnostic labelling is a harmful process which transforms attributes about individual experiences into symptoms and an identity centred on illness that hinders recovery (Wisdom \& 
Green, 2004).

The power of adults, as parents and professionals, to describe and define, adolescent behavior as 'disordered' is greatly concerning. There is an overwhelming amount of research exploring the pathologization of adolescent behaviour, however, most research in this area still reflects psychocentric assumptions. The increase in adolescents being diagnosed with psychiatric disorders begets further exploration. By looking at our history, it is evident that societal understandings of childhood evolve and change over time (Timimi, 2006). Put simply, what was considered 'normal' behaviour at the time when our ancestors were adolescents is likely to be very different from what 'normal' behaviour is considered now. Looking at our changing constructions of childhood implies that the meaning we give to behaviour changes over time, rendering to be suspect the idea that we know what a universal 'normal' is (Timimi, 2006).

\section{Participation in Treatment Decisions}

In the literature which focuses on the experiences of adolescents within the psychiatric system, there are few which do not make mention of their desire to be involved in the decisions of their treatment. The rights of patients regarding their healthcare are a highly contested issue, even amongst adults (Costa, 2013). Years of advocacy by human rights groups have fought for the ability for 'Mad' individuals to be given the same rights as individuals with physical health issues (Costa, 2013). Despite some gains in policy development, adolescents remain vulnerable to the paternalistic belief that adults undeniably know better than young people about what is 'in their best interest’ (Breggin, 2014).

In a study conducted on adolescents' perspective on the use of psychiatric medication as treatment, many adolescents expressed distrust of the medication they were prescribed (Lefrancois, 2006). Participants expressed concerns surrounding the side effects they were 
experiencing as well as whether the medication was beneficial to them. Most notably, adolescents whose mental health was improving questioned whether their progress was accredited to their own efforts or merely a result of the medication. Regardless of repeated efforts to have their medication reviewed or stopped, adolescents reported practitioners' insistence on all patients taking medication;

I don't like the idea that it changes who I am. They [practitioners] say its fine but I don't want to lose something that is me... I don't think that medication is the answer and I think people should be given a choice whether we want medication or not. I mean, it's your body and they shouldn't threaten you (Lefrancois, 2006, p.5).

The experience of not being listened to and dismissed by mental health professionals is reflected in a study conducted with forty African American youth and their mothers on their perception of and experience with mental health services (Thompson, Dancy, Wiley, Perry \& Najdowski, 2011). All participants reported feeling ignored or dismissed in at least one, if not most of their interactions with counsellors or other mental health professionals (Thompson et al., 2011). Unfortunately, the researchers in this study chose to analyze their findings using a psychocentric lens. Rather than looking for ways to better participants' experiences of counselling, researchers attributed the participants' experiences to personal misunderstandings. Therefore, the researchers reinforced their participants' experiences of being ignored while validating the sanist assumption that 'Mad' individuals are innately disordered and untrustworthy sources of legitimate knowledge.

In an ethnographic research study looking at the ways in which children's participation rights are incorporated within an adolescent mental health inpatient unit, researchers found that practitioners had reinterpreted the concept of 'participation' to suit an agenda convenient to them 
(Lefrancois, 2008). Their efforts to increase patient participation manifested in practitioners asking for client input on the activities conducted in group work. Despite appearing like a genuine initiative, participants reported feeling as though their opinions were only taken seriously when they aligned with the views of their practitioner. Participants also reported being forced to participate in group activities when they did not want to participate. It soon became apparent that 'participation' was nothing more than a superficial attempt to make patients believe they had a voice in the terms of their treatment, while actually being confined to the choices within the treatment plan already decided for them.

This rhetoric is likewise exemplified in a study conducted on adults' retroactive views of treatment for anorexia nervosa (Offord, Turner \& Cooper, 2006). One of the most common complaints participants stated to researchers was the tendency for practitioners to consistently attribute participants’ opinions about their treatment to symptoms of their disorder (Offord et al., 2006). These experiences speak to a much larger theme of social control which is enmeshed with the psychiatric system. In a study conducted on the experiences of adolescents living in an inpatient psychiatric facility, participants described feeling restricted by the lack of privacy they were given (Haynes, Eivors \& Crossley, 2011). Participants described the worst aspect of being admitted as the process of always being observed. This caused participants to feel like they were being studied and scrutinized which in turn resulted in nonadherence to their treatment (Haynes et al., 2011).

The feeling of being controlled and watched is echoed in a study conducted on adolescents’ perceptions of the referral and admission process (Salamone-Violi, Chur-Hansen \& Winfield, 2015). One adolescent in this study recalled the police arriving at her home and carrying her into the ambulance (Salamone-Violi et al., 2015). The notion that 'Mad' individuals 
are not able or competent to make decisions for themselves is widely insinuated throughout psychiatric discourse and in scholarship which uses a positivist lens to explore the experiences of 'Mad' individuals.

To depreciate the opinions of 'Mad' individuals regarding their health care decisions reinforces psychocentrism and sanist assumptions. In a qualitative study, Lauren Gonzales et al., (2014) conducted focus groups to explore microaggressions experienced by 'Mad' individuals. Microaggressions are subtle verbal or behavioral communications of belittling messages to people based upon membership in a socially marginalized group (Gonzales, 2014). Gonzales (2014) uncovered the small everyday microaggressions that are used by socialization to discredit, demoralize and devalue the thoughts and opinions of 'Mad' individuals. Sanist microaggressions include; invalidating the experiential reality of 'Mad' individuals, assuming 'Mad' individuals have lower intelligence and the idea that 'Mad' individuals are dangerous. Each time an adolescent is dismissed by a mental health professional, they experience a sanist microaggression (Gonzales, 2014).

The experience of sanist microaggressions are emphasized in the findings of a study which explored experiences of discrimination within mental health treatment programs (Holley, Tavassoli \& Stromwall, 2016). Participants reported feeling ignored, disrespected and infantilized by staff. Participants further described incidents which demonstrated that staff assumed patients were not intelligent, "People would often explain things very... elementary when I was able to grasp complex concepts quite easily” (Holley et al., 2016, p. 316). As previously mentioned, adolescents are susceptible to adopt and internalize their experiences of their mental health treatment, therefore, this study is critical to our understanding of how psychocentric assumptions may influence identity and self-perception in adulthood. 
Irrespective of their intention to address the neglect of patient rights, researchers still resort to explaining experiences of oppression as experiences of stigma and pay no attention to the underlying foundation on which stigma is based. I failed to find a single study which discussed its findings in connection to sanism. The failure of these studies to make links to the overarching systemic forces which contribute to individual experiences of emotional distress often results in the use of 'psy' discourse to blame individuals for their socially produced suffering. However, the experience of sanism is not experienced in isolation and sanist microaggressions are even further exacerbated when coupled with intersectional experiences of race, sexual orientation, class and other identities.

\section{Intersectional Experiences of Madness}

The practice of psychiatry is dominated by preoccupations of white Western colonizers. Therefore, our understandings of health, illness and normalcy are laden with assumptions implicit in patriarchal and paternalistic values (Coppock, 2004). It is not hard to imagine how reliance on the medical model's understanding of normalcy would differently impact individuals whose gendered, racialized, and queered bodies fall on the peripheral of dominant discourse.

The potential harms caused by the dependence on heteronormative notions of normalcy are exemplified in Lefrancois' ethnographic study of children's experiences in a psychiatric inpatient unit in the UK. Lefrancois (2014) uses Queer Theory to exemplify the susceptibility of bodies, which fall on the peripheral of dominant discourse, to increased pathologization and psychiatrization. Lefrancois (2014) demonstrates this susceptibility with an example of a child who psychiatrists predicted to develop borderline personality disorder. Even though currently

showing signs of good 'mental health', this child was administered neuroleptic drugs and assigned to treatment. After over a year of psychiatrization, this child disclosed that his distress 
was related to his fears of coming out as being gay (Lefrancois, 2014). This example speaks to the harms caused by heteronormative psychiatric discourse on bodies which face intersectional oppressions.

The dangers of psychocentric approaches to health is further evidenced in a three-year qualitative study conducted with Indigenous communities in the context of a cultural and physical activity program in Toronto. Lavallée (2010) participated in sharing circles with the community and explored stories of pain, identity, healing and the stigma of identifying as Aboriginal. This study highlights the urgent need to look beyond Western notions of health to include Indigenous understandings of well-being. Indigenous concepts of holistic health sharply contrast Western notions of 'mental illness' and these foundational contradictions serve to sustain colonizing practices and anti-Indigenous sanism. Therefore, recognizing Indigenous ways of knowing and being, which include understandings of mental health is essential to stopping the harm and damage being done to these communities.

Individuals with interlocking experiences of oppressions, such as race and socioeconomic status, are explored in a study conducted with low-income African-American caregivers. The study particularly looked at caregivers' experiences of their child being referred to mental health services by a school counsellor (Tucker, 2009) With increasing societal pressures for community involvement in mental health care, school counsellors have become key figures in the referral of children to mental health services (Ritchie \& Partin, 2004, as cited in Tucker, 2009). Most public schools in America, even predominantly minority schools, seem to function from a cultural view based on white, middle class values (Carter, 2003). The caregivers in this study illustrate the problems of cultural dissonance within the school system, as well as, a lack of understanding of the responsibilities and barriers faced by low-income individuals. This lack of understanding was 
demonstrated in the school's expectation that the caregivers would have no problem accessing mental health services on their own and without any help from the school. Participants reported being blamed by the school for the lack of time they spend at home and expressed feeling fearful that if they could not access mental health services for their sons or grandsons they would likely be suspended or expelled (Tucker, 2009). This study's findings reflect the notion that psychocentric understandings of illness are inexplicably linked with experiences of poverty. Nowhere in this study does it make mention that the school or researcher fathomed that the child's experience of 'mental illness' may actually be a response to their experience of poverty.

The unique experiences of Black individuals in their encounters with psychiatry is articulated by Abdillahi, Poole and Meerai (2017). Anti-Black sanism explains the over pathologization, over representation and over diagnosis of Black individuals in the mental health system because of continued 'race thinking' in psychiatric discourse (Abdillahi et al., 2017). Racial taxonomies are a product of colonialism and despite lacking any scientific basis, continue to exist within the context of psychiatric discourse. In a study conducted on the help-seeking behaviours amongst Black adolescents diagnosed with depression, participants expressed a distrust of white counsellors (Lindsey, Korr, Broitman, Bone, Green \& Leaf, 2006). The adolescents in the study explained that they distrusted white counsellors because of their lack of understanding or appreciation for cultural differences, “I don’t think [white professionals] can understand where I'm coming from” (Lindsey et al., 2006, p. 54). This sentiment is echoed in many studies conducted with adults on their experiences of racial discrimination within mental health counselling relationships. Constantine (2007) examined the relationship among Black clients' perceptions of their white counsellors with respect to racism in counselling. This study draws attention to a form of racism, called aversive racism. Unlike overt forms of racism, 
aversive racism is described as "whites harboring of unconscious or preconscious negative racial feelings and beliefs toward people of color, despite the fact that they may perceive themselves as egalitarian, fair and nonracist” (Dovido \& Gaertner, 1986; Jones, 1997; Whaley, 1998, as cited in, Constantine, 2007, p. 2). Aversive racism is commonly expressed through racial microaggressions, which refers to subtle, everyday exchanges that convey insulting and demeaning messages to people of color (Franklin, 1999; Pierce et al., 1978, as cited in, Constantine, 2007). Participants of the study expressed experiencing racial microaggressions within counselling relationships and the undue impact it has on the therapeutic alliance. Constantine (2007) further demonstrated that the harm that is caused by having to deal with racial oppression within a relationship intended to facilitate human growth is profoundly more harmful than the experience of racism in other environments.

The lack of awareness of the cultural values embedded in our understandings of 'normal' leave racialized, Indigenous, queer, trans and other non-dominant identities vulnerable to greater scrutiny and pathologization as their 'normalcy' depends on their ability to perform cisnormativity and 'whiteness'. This is especially concerning when it comes to the undue pathologization and misdiagnosis of adolescents who may lack the cognitive ability to perceive their diagnosis as a product of racial bias (Surko, Ciro, Blackwood, Nembhard \& Peake, 2005). This theme of the literature reinforces the need for approaches that honor experiences of intersectional oppression faced by survivors of adolescent psychiatry. This theme also emphasizes the need for researchers to look critically at the systems that perpetuate the conditions and experiences which they are exploring.

\section{Gaps in the Literature}

These scholars noted above speak at great lengths about the experience of adolescent 
psychiatry. The widening of diagnostic criteria to pathologize undesirable behavior, neglect to value the rights of patients and intersectional oppression caused by Eurocentric understandings of mental health, all present deeply troubling experiences faced by psychiatrized adolescents. Nevertheless, apart from the focus on anti-Indigenous racism (Lavallée \& Poole, 2010) and antiBlack sanism (Abdillahi et al., 2017), much of the research presented in this literature review fails to take a critical approach to understanding experiences of madness. The literature does not do an adequate job of linking mental health stigma to mental health oppression, therefore, further oppressing 'Mad' individuals by reducing their experiences to symptoms of their disorder. By the same token, researchers all too often resort to using psychiatric terminology to describe the experiences of their participants. Consequently, participant accounts are framed as 'perceptions' implying that their experiences may not actually be happening and are merely a matter of their own disordered perception. Mental health oppression is rarely named in the literature as sanism, leaving mental health stigma as a poorly defined concept that never responds to its oppressive roots. The lens of sanism as mental health oppression is largely missing in the literature and is fundamental to this research study.

Many participants of the studies discussed in this review called attention to the external struggles they were experiencing, such as poverty, racism, adultism and heteronormativity in tandem with experiences of madness. Nevertheless, participants' mental health was discussed by researchers as internally produced -- as if their experiences of mental health were somehow distinct from the social conditions that shape those experiences. In this way, researchers neglect to account for the systemic processes involved in the oppression of 'Mad' people and render themselves hopeless in achieving their stated objective of 'helping to provide more effective mental health services'. This demonstrates a clear need to explore the unique experiences of 
intersectional oppressions to deconstruct how psychocentrism sustains the hegemony of white Western values by pathologizing individuals struggling with socially produced inequities.

To acknowledge someone fully means considering their realities contextually, and looking for intersecting experiences of privilege and oppression. This research will further this objective by centering the experiences of psychiatrized adolescents through a framework that honors the complexity, plurality and fluidity of their experience while working to deconstruct the political agenda embodied by the 'psy-complex'.

Based on this literature review and the identified gaps, I want to know how individuals have made sense of their experiences of psychiatrization as an adolescent. Considering the susceptibility for adolescents to internalize social discourse, the experiences during adolescence are likely to impact our perceptions in adulthood. As such, the research question for this project is: How do individuals retroactively understand the influences of psychocentric adolescent mental health care in adulthood? 


\section{CHAPTER 3. THEORETICAL FRAMEWORK}

My theoretical framework is comprised of, Anti-Racism, Anti-Colonialism and Mad Studies. My arrival at this theoretical framework was through a journey of beginning with commitments to Critical Mad Perspectives (CMP) (Dydick, 2014). However, as I went through my MSW program, I came to realize that CMP, did not centre racism and colonialism, which are at the heart of sanism. For this reason, my theoretical framework will focus on racism, colonialism and sanism as key oppressions that underpin contemporary mental health discourses.

Psychiatric understandings of mental health are so ubiquitous that they are rarely questioned and thus, it would not be a stretch to say that contemporary society has been colonized by the 'psy-complex'. Research on adolescent experiences of mental health care has historically been limited to positivist frameworks which psychiatric assumptions are based. The 'psy-complex' derives from the work of French philosopher, Michael Foucault, who analyzed the role of the social and 'psy' professions in regulating social behaviour (Hook, 2007). The ability to regulate social behaviour is achieved through the pervasiveness of positivist epistemology.

Positivism and psychocentric approaches to mental health have been under scrutiny since the 1950's (Foucault, 1954; Goffman, 1963). Recent studies have hinged upon the work of seminal scholars who have spent decades investigating the roots of psychiatry and the injustices sustained through prevailing power dynamics (Breggin, 1991; Fernando, 2010; Frances, 1981; Szasz, 1979). These scholars reveal that progressive research must move beyond the understanding of madness as a fixed construct towards an approach that honors the fluidity and plurality of individual experiences of madness, while situating these experiences in a colonial context. Through the use of a Mad Studies lens, I intentionally diverge from biomedical 
explanations of mental health and the centrality of stigma which is so often seen within scholarship. Those who are stigmatized face increasing social obstacles which can often pose more challenges than the 'illness' itself (Livingston et al, 2010). Discrimination, poverty, social isolation and rejection are just some of the consequences stigmatization has been shown to result in (Livingston et al, 2010; Pinfold \& Byrne, 2005). However, as critical Mad Studies scholars point out, to focus on stigma is to miss the point of the widespread human rights abuse and oppression often experienced by people with mental health issues (Poole, Jivraj, \& Arslanian et al., 2012). By re-conceptualizing our understandings of mental health stigma and discrimination, we become increasingly aware of the larger system of oppression known as sanism. This form of oppression is often invisible to the greater population which speaks to the normalization and entrenchment of psychocentric discourse. However, in recognizing the undeniable ties between psychocentrism and ongoing colonization and institutional racism, experiences of madness must be situated within this context.

The following sections will map out this framework by exploring (1) the necessity of problematizing psychocentric understandings of madness, (2) the limits of Mad studies as an alternative framework, (3) Critical Mad Perspectives as an addition to Mad studies, and (4) digging deeper, centering anti-racism and anti-colonialism.

\section{Problematizing Psychocentric Understandings of Madness}

The supremacy of madness by psychocentrism frames "mad people as a collection of chemical imbalances needing to be corrected in a capitalist system that prizes bourgeois conformity and medical model 'fixes' above all” (Menzies et al., 2013). Psychocentrism is supported by the epistemological prestige of positivism gained by the pre-eminence of natural sciences. The dominance of psychocentrism has been proven problematic for various reasons 
such as classificatory ambiguity, conflicting empirical data, subjective ideas about normalcy and controversial use of psychiatric interventions (Rimke, 2016). Psychocentric approaches also neglect the direct ties of psychiatry to colonization and thus, continue to reinforce colonial power relations. The strict focus on the individual as the source of the problem is especially problematic and has been theorized by Rimke (2016) as a tool of neoliberalism. Medicalization and psychiatrization of morality shares values of neoliberalism whereby individuals are free and autonomous consumers responsible for their own health and distress (Rimke, 2016). Many individuals face an array of structural and institutional issues from financial insecurity, unemployment, lack of secure housing, sexual or racial violence (Rimke, 2016). The failure to connect social structures to individual experiences of distress is to exempt the government from social responsibility and accountability.

Psychocentrism presents an approach to mental health which blames and pathologizes individuals for their experience of socially produced suffering. This understanding of mental health is exactly what this work seeks to call into question. What's more, individuals who are subjected to psychiatrization are often vulnerable to epistemic injustice, in which someone is wronged specifically in their capacity as a knower and are framed as untrustworthy or unreliable sources of knowledge (Fricker, 2007). The biomedical model of mental health positions psychiatrists as the 'expert' knowledge holders and consequently, subjugates Mad knowledges. With a psychocentric approach, the psychiatrist is seen as being more in touch with reality and thus the patient is consistently viewed through a lens of a diagnosis and illness rather than legitimate source of knowledge (Fricker, 2007). The psychiatrist’s ability to re-frame stories through a diagnostic lens presents a crucial problem. Within the context of adolescents, this is especially worrisome. Adolescents who already hold a position of powerlessness are particularly 
vulnerable to epistemic injustice, which often leads them to internalize pathologizing

explanations of their distress. The adoption and internalization of psychiatric discourse by means of surviving the mental health system will be explored in this study.

\section{Mad Studies as a Counter Discourse}

Mad Studies emerged as a movement in the 1960s as a grassroots activism to respond to the oppressions faced by individuals subjected to the psychiatric system (Menzies et al., 2013). The Mad movement challenged the notion that sanist discourses of treatment presented 'best practices' in recognizing that there are many ways of understanding, responding to and addressing individual experiences of distress. The term 'Mad' has a history of being a derogatory method of addressing, oppressing and pathologizing individuals with mental health challenges (Menzies et al., 2013). However, activists reclaimed the term 'Mad' as a political tool to reject pathological explanations for individual experiences of mental health (Menzies et al., 2013). This can be compared to the re-claiming of the word 'queer' within the LGBTQI2S communities. Mad Studies presents an exciting opportunity to honor the lived experiences of 'Mad' individuals by centering their voices while working to dismantle oppressive power relations which support the ongoing marginalization and pathologization of individuals experiencing emotional distress. It is only recently that this area of scholarship entered the world of academia, through selfidentified 'Mad' individuals such as David Reville. Reville is accredited for coining the term 'high-knowledge crazies' to refer to 'Mad' identified people who are doing or have done postgraduate work (Menzies et al., 2013). Mad Matters: A Critical Reader in Canadian Mad Studies (2013), offers strategies and methods to explore experiences of psychiatrization, dismantle psychiatric and sanist discourse, along with, promoting the agency and autonomy of 'Mad' individuals. Mad Studies scholarship is abundant with perspectives that challenge the dominance 
of psychocentrism and mental health injustices. However, despite Mad Studies commitment to upholding the rights of 'Mad' individuals and diverse explanations for emotional distress, Mad Studies has limits to addressing the diverse experiences of social injustice that are pathologized through psychocentrism. It is this reason that I initially chose to utilize an expanded notion of Mad Studies, known as Critical Mad Perspectives.

\section{Intersectionality \& Madness}

The Mad movement and Mad studies, have historically been taken up by white educated middle class individuals who are privileged with the ability to self-identify as 'Mad' (Gorman, 2013). This dynamic has made it increasingly difficult for individuals who fall outside of that demographic, to find a space within a movement where their experiences are adequately and meaningfully acknowledged. Recent scholarship has evidenced the undeniable connection between diverse experiences of oppression and madness. Scholars have demonstrated that psychocentrism uniquely impacts individuals who differ based on interlocking experiences of oppression; such as, race, class, gender, sexual orientation etc. (Gorman, 2013; Rimke, 2016). These experiences of sanism are unique based on additional structural, institutional and systemic forces which contribute to the likelihood and severity of psychocentric oppression. Despite great efforts to challenge sanist discourse, Mad Studies falls short of being able to sufficiently account for these unique experiences.

In an attempt to address intersectional experiences as unique from the experiences of those who belong to the dominant population (read white, middle class, cisgendered), Didyk (2014) expanded on the Mad Studies framework to include intersectionality, critical social work and anti-oppressive practice. However, in spite of my initial excitement with CMP, Ahmed (2004) helped me to realize that, "the language we think of as critical can easily 'lend itself' to 
the very techniques of governance we critique.” Ahmed (2004) explains that white researchers often mistakenly assume that if our studies are proposed as 'critical' that we have somehow protected ourselves from doing- or being seen as doing- socially unjust research. Thus, I came to understand that Critical Mad Perspectives may not be as critical as it proposes to be. The motivation behind expanding Mad Studies to include intersectionality, anti-oppression and critical social work perspectives was the desire to explore experiences of sanism that were conflated with experiences of racism, classism and other forms of oppression. Although CMP may allow for that exploration, it remains limited in its ability to challenge the discourse and power dynamics which it seeks to disrupt. Despite offering a framework to consider the intersections between race and madness, Critical Mad Perspectives fails to locate these intersections within the social and political contexts of colonization.

\section{Digging Deeper}

To rely on a Eurocentric conceptualization of history not only denies the colonial roots of psychiatry, but allows for white supremacy to remain unexamined. An anti-colonial framework, therefore, will aid in my intention to interrogate psychocentrism as an ongoing colonial project. Furthermore, Pon, Giwa, and Razack (2016) helped me to understand that anti-oppression was created in response to Black social workers' efforts to integrate anti-racist approaches into practice. Instead of using race as the central lens through which to view intersecting oppressions, an anti-oppression approach entails a broad view of oppression and discrimination, with the understanding that human experiences are shaped by an array of intersecting identities (Carniol, 2010; Hick, 2010, as cited in, Pon et al., 2016) The shift from anti-racism to anti-oppression permitted white social workers to remain unthreatened and innocent in the maintenance of white supremacy, while able to hide under the guise of an 'anti-oppressive perspective'. To de-center 
conversations about race, is to leave the system of white supremacy intact. Thus, anti-oppression is not only insufficient to address psychocentric connections to colonialism and racism, but in fact, reinforces hegemony. As a result of these realizations, I have decided to go deeper. Rather than rely on a theoretical framework which allows for me to maintain my status as 'innocent' in processes of colonization, racism and oppression, I have decided to utilize anti-racism, anticolonialism and Mad Studies frameworks, in an attempt to implicate myself in these processes. Anti-racism emphasizes race as the entry point through which one understands and addresses interlocking systems of oppression, while highlighting the need to recognize race and difference as matters of power and equity (Pon, Gosine, \& Phillips, 2011). Anti-colonialism represents a social, cultural and political resistance to the ideology and practice of colonialism (Ashcroft et al., 1995; Dei, 2000; Hart, 2009, as cited in Pon, Gosine \& Phillips, 2011). Both anti-racism and anti-colonialism stress the importance of critical self-reflexivity and the significance of whiteness, including white privilege (Dei, 2008, as cited in, Pon, Gosine \& Phillips, 2011). Thus, this decision has not only encouraged a deeper examination of these interlocking systems of oppression, but propelled me to interrogate myself as complicit in these processes as well. 


\section{CHAPTER 4. METHODOLOGY}

To address my research question, the following study was designed to expand our theoretical understanding of psychocentrism as an approach to adolescent mental health care. The following work will rely on qualitative research that uses a phenomenological methodology. Interviews with adults who have experienced adolescent psychiatry will be used as a method to inform the research. A phenomenological methodology interprets an experience through the stories told by the participants. The focus of phenomenology is "on the subjectivity of reality, continually pointing out the need to understand how humans view themselves and the world around them” (Willis, 2007, p. 53). Phenomenology is known to bring individual perceptions to the foreground, thereby challenging structural or normative assumptions. This is especially pertinent to this study which aims to explore how psychocentric approaches to adolescent mental health care, influences individuals in adulthood, in addition to how that experience is shaped by intersectional oppressions. Consistent with the study's theoretical framework, this study aims to prioritize the perceptions, understandings and experiences of participants which are central to phenomenology.

Phenomena are not bound to a particular period in time or event in history, but can be utilized to explore a shared experience or condition such as, the experience of cancer. Therefore, research conclusions will not investigate the situation as a phenomenon, but rather the experiences of the participants as they experienced that phenomenon. The insight gained through participant understandings will allow for a deeper understanding of the phenomenon through an analysis of those experiences. As Willis (2007) explains "The focus is thus on understanding from the perspective of the person or persons being studied” (Willis, 2007, p. 107). Through this 
process, I hope to gain insight into the essence of the phenomenon under investigation (Creswell, 2013).

Prior to initiating the following work, I was successful in obtaining approval by the Research Ethics Board at Ryerson University. My research is guided by the question; How do individuals retroactively understand the influences of psychocentric adolescent mental health care in adulthood? Specifically, my intent is to uncover the unique impact psychiatric treatment may have in adolescence, when individuals are in the process of identity formation. In interviewing this demographic, I hope to distinguish important perspectives of how these individuals understand their experience of psychiatrization- specifically as it relates to their lives in adulthood. Using a qualitative research design, I conducted interviews with 3 individuals, over the age of 18, who identify as having experienced psychiatrization in adolescence but who no longer have a connection with the psychiatric system. The individual, semi-structured interviews lasted between 1.5 to 2 hours. I used an interview guide consisting of a list of questions related to participant understandings of their experiences (see Appendix A). These interviews were audiorecorded so that I could transcribe the interviews for critical examination and in-depth analysis of the text. The completed research paper is a descriptive analysis and reflection upon the interview answers provided by participants and how these answers fit with, contrast, or provide new perspectives upon this emerging area of study.

Most of the existing research on this subject is situated within a positivist epistemology which fails to examine the potential implications of its use. The rationale for my approach to use qualitative methods is to capture a more nuanced, detail rich, personal, in-depth perspective of how individuals understand their experiences of adolescent psychiatry devoid of pathologization. As such, this MRP brings the voices of individuals into the field of study and, hopefully, inspire 
further, more detailed research than that which is currently available. Furthermore, I expect/hypothesize that this more open framework of questioning will allow for heretofore silenced voices of critique to emerge (a perspective strongly lacking in present research and very likely reinforced by research design).

Having already been involved with the Mad Pride community in Toronto, I utilized a snowball method of recruitment by contacting some of my peers and asking them to extend recruitment invitations to others that I will not have had a direct relationship with. Also, my present peer group of Master of Social Work students were provided with copies of my recruitment script, which they were invited to share amongst individuals who they believed might have fit the criteria and with whom I have had no direct professional relationship with. Interested participants reached by the snowball method were provided with both my email address and phone number and were able to contact me by their preferred method. This method provided an initial consent by participants to share contact information with me and for them to ask any further questions. Further written consent was obtained upon agreement to participate in an interview.

The recruitment transcript (see Appendix B) was accompanied with the consent agreement form (see Appendix C), which outlines in greater detail the research study and its requirements of the participant. These forms were provided to the potential participant once they contacted me with an initial interest for more information. They had ample time to review the information and ask questions before agreeing to participate.

My participants were purposefully selected based on their eligibility and social location to best respond to my research question. For findings to be analyzed in respect to participant experiences of intersectionality, it is my aim to select a group of diverse participants. By diverse, 
I mean that participants differed along the lines of structural factors such as race, gender and sexual orientation. The information was kept confidential and securely stored electronically with password protection - it will all be destroyed prior to publication. Personal and identifying information is not used in the research publication where, instead, pseudonyms replace the names.

The audio recordings were password protected on the audio device and uploaded to password protected audio files. These audio files were deleted once the transcriptions were completed within a week of the interview being audio-recorded. The transcriptions were kept as password protected files up until the final draft of the paper was completed and submitted to the School of Social Work of Ryerson University. Once the final paper was submitted to the School of Social Work of Ryerson University the transcriptions were destroyed.

I transcribed the audio recordings within a one-week period following the interview. Consistent with Chase (2003), I listened to the audio tape multiple times before engaging in a process of line by line coding. This process involved listening closely for natural stopping points, changes in speech or tone, and changes in subject matter (Chase, 2003). Consistent with Chase, I then started to write 'codes' in the margins of the transcription, as well as, interpretive comments. Interpretive comments describe researcher impressions, thoughts or questions that may have come up and are relevant to the transcription. This was done with extreme caution to avoid interpreting participant voices and experiences. It is essential that participant voices be central to the analysis so these comments were not aimed at interpreting their experiences, but focus mainly on descriptions and my reactions. Once the transcriptions had been read multiple times and all the codes had been identified, I began to analyze the data. From this point, I started to pull together codes and comments into broad categories. To explore the ways in which each 
interviewee understands their meaning, each category was looked at independently in relation to each of the interviewees. This process allowed for an analysis of the similarities and differences between how each interviewee understands and relates to a category. Furthermore, by compiling the data into categories, I was able to see if the data strengthens and supports the identified categories. From there, I looked for overlap and reduced any redundancy by collapsing codes into a smaller number of themes. These themes were used to discuss the findings which were collected from participant interviews. 


\section{CHAPTER 5. FINDINGS \& ANALYSIS}

The interviews conducted with Cassandra, Bailey and Jane all provided rich insights that allowed for a critical analysis of how psychocentric perspectives impact an individual who has been psychiatrized in adolescence. Through an Anti-Racism, Anti-Colonialism and Mad Studies perspective, this paper will explore the impact that psychocentric approaches to adolescent mental health has on an individual in adulthood. Through this exploration, I aim to highlight the Eurocentricity inherent to psychocentrism, while problematizing its application in a diverse context, such as Toronto, Canada. This analysis will also be used as an opportunity to interrogate power, privilege and positionality in relation to the research process.

As the findings are discussed, I will draw connections between psychiatrization and colonial ideologies upheld by white supremacy. With that in mind, I offer a brief introduction to each of the participants, to center the contextual identities that informed our discussions.

Cassandra identifies as a racialized, gender fluid, queer individual and uses the pronouns they and them. They would be read as "Brown" and presents in their 30s. Bailey is someone who identifies as a white, cisgender, pansexual woman and uses the pronouns she and her. She would be read as "white" and presents in her mid 20s. Jane is someone who identifies as an East Asian, agender, pansexual individual and uses the pronouns she and her. Jane would be read as "Asian" and presents in her early 20s.

As my research question proposes, I will outline the impact that psychocentric approaches have had on my participants as they pertain to four main themes; internalization; identity, recovering from 'recovery' and resistance. Throughout my interviews, participants consistently spoke about the impacts of having an authoritative body of medical professionals describe their experiences in pathologizing ways, particularly their internalization of psychiatric 
discourse and the sustaining impacts of this internalization. Moreover, each participant described various ways that they have been strategic in the way that their experiences have forced them to negotiate their identity and be strategic when talking about their mental health. Another theme that will be explored in my analysis is the shared experience of having to 'recover' from the mental health system, in addition to, the influence this experience has had on perceptions of helping professionals. Lastly, I will explore the various ways that my participants have acted in resistance to psychiatric discourse as a result of their lived experiences.

Analyzing, interpreting and representing data is inevitably a subjective process and the way participants and experiences are represented depends largely on the researcher’s interpretation (Chadderton, 2012). Hence, this study, with which I aimed to challenge white supremacy and prioritize participant voices, is recentering my own white voice. I therefore aimed to analyse the data in a way which situated experiences within a colonial context, while distinguishing between participant voices and my interpretations of it. Additionally, I was careful not to consider participant voices or experiences as representative of a group to avoid essentializing individual experiences and reinforcing the falsehood of homogenous groups. I was also careful not to consider participant voices as 'authentic' reflections of their identities because to believe that researchers can access authenticity, neglects to consider the role of the researcher in the research process and the exploitative nature of research. Thus, I have situated myself in this research and text, rejecting the notion of neutrality or objectivity by exploring racial positioning and my complicity within white supremacy.

\section{Internalization}

Diagnoses, as defined by the American Psychiatric Association (2017) entail a set of symptoms and criteria for a 'mental disorder', however, all participants described their diagnosis, 
not as something that described their experience of distress, but as a prescription for who they were. The expectation that individuals will assume all aspects of an assigned diagnosis demonstrates the entrenchment of sanism in our social construction.

During the interview process, I asked how participants felt after initially receiving a psychiatric diagnosis. Cassandra, immediately named the reaction it had on them, "I always internalized it. It was a source of pain because of all of the connotations that go along with schizophrenia. It was like 'Oh my god. I’m one of them'. Cassandra spoke candidly about their awareness of already having internalized psychiatric discourse as it pertains to people with schizophrenia, prior to receiving the diagnosis. I believe this knowledge speaks to the extent to which sanism and psychocentrism is rooted within our everyday understandings of mental health. What I also found telling in this passage, was the statement "one of them" and the implication that people diagnosed with mental health issues are somehow distinguished from those who not. The 'us vs. them' dynamic is perpetuated by sanism and thus, supports the maintenance of white supremacy through processes of marginalization (Rimke, 2016). Cassandra also alludes to the power dynamics inherent to the diagnostic process (Coppock, 2004). 'Psy' professionals have been exalted to such an extent that society rarely questions or scrutinizes the reliability or validity of what is stated as 'truth'. Thus, young people are increasingly vulnerable to psychiatrization given the extent to which the medical model is utilized in adolescent mental health interventions. On another visit to a psychiatrist, Cassandra recalled;

She wrote schizoaffective disorder, social phobia, OCD, possible depression and in the end, there was about seven or eight and so I walked out of this thing and I'm looking at this sheet and I'm like 'whoa there must be a lot wrong with me, like I must be crazy you know?' 
Sanism perpetuates beliefs about people who are deemed 'mentally ill' such as, violent, unintelligent, lacking self-efficacy, and various other negative connotations (Poole et al., 2012). Cassandra spoke earnestly and candidly about the impact this discourse had on their initial thoughts about receiving a diagnosis. It is apparent that Cassandra did not merely see this as a diagnosis describing their symptoms, but an attribution of all the negative connotations surrounding schizophrenia.

Similar to Cassandra, Jane described the moment when she first was diagnosed with Borderline Personality Disorder (BPD) and conducted a Google search to learn more about the diagnosis. She recalled reading something along the lines of, People with BPD are horrible people, you never want to be with them or close with them at all. They can't have relationships or friendships because they will $\mathrm{f}^{* * *}$ with you and they are narcissistic and selfish and all these things horrible things and I was just like, oh my god, I'm all of these things!

Jane spoke about the significant influence reading this had on her, "I was so scared and I was sitting in my room thinking that I should never have a social life again because I'm a horrible person and I don't want to hurt people.” It is evident that like Cassandra, Jane too, describes the power dynamics inherent to the diagnostic process and the susceptibility to accept this knowledge as truth. Jane further discussed how the diagnosis and associated symptoms caused her to constantly worry about her actions and behaviours,

I feel like it's seriously screwed with me because even now sometimes I'm catching myself doing things and I'm like oh my god this could be narcissistic or I'm taking up too much space or talking to myself too much and it's all because of my BPD and I just pay so much attention to it. 
Jane recognized that her experience with mental health professionals has caused her to feel like people should be wary of their interactions with her, "I feel like I have to warn people when they get into a relationship with me. It's like 'hey I've got BPD so you gotta like know that before we start dating.'” From my perspective, Jane not only internalized pathological understandings of her thoughts and behaviours, but also the shame that is reinforced by the insistence that experiences of distress are a sole result of individual shortcomings. Jane described a constant struggle to determine whether her actions resemble symptoms of her diagnosis, "Maybe it is my BPD or sometimes it may just be myself or is it the BPD or is it myself or is it the BPD?” The frustration of feeling as though one cannot know or trust whether one's actions are 'normal' or 'disordered' is shared amongst participants and will be explored in latter themes. Internalized psychiatric discourse may be a lifelong struggle, as Bailey describes it; “if you're labeling me as a disorder then I'm going to internalize that message and I don't even know if you can recover from that, like how do you recover from being disordered?” In this statement, Bailey, perhaps unbeknownst to her, helped me to recognize an inherent flaw of psychocentric approaches to mental health care. After all, if a 'mental illness' is determined by genetic makeup as psychocentrism claims, how can one possibly propose to alleviate someone from that?

\section{Recovering from 'Recovery'}

'Recovery' discourse, much like psychocentrism, undeniably aligns with neoliberalism through an emphasis on personal responsibility and Western ideals of individualism (Poole, 2011). Nonetheless, I will use the term 'recovery' in quotations, intentionally to demonstrate my skepticism of the very notion that emotional distress represents something we must 'recover' from. Through this interview process, I have learned that lived experience with the mental health system is a lifelong process. That is not to say that an individual is subjected to be a patient of 
the mental health system for their entire life, but that an individual will live in a process of 'recovery' from having been deemed 'ill' by society. The constant struggle of deciphering whether one's behavior is 'normal' or 'disordered' was frequently highlighted throughout the interviews. Psychocentrism insists that mental distress is a result of inherent biological characteristics. This thinking can be traced back to beliefs of biological markers of race and their use to justify colonization (Fernando, 2012). These biological markers allowed for psychiatry to emerge within a context of 'helping' to civilize racialized 'others' (Fernando, 2012). In spite of little evidence supporting pathological determinism, it is entrenched within a psychocentric approach to mental health and continues to perpetuate the unjust pathologization and institutionalization of individuals deemed 'deviant' (Fernando, 2012). Thus, the power to define who is 'civilized' and who is 'deviant' positioned whiteness as the norm to which others should aspire and remains a means to maintain white supremacy.

The belief that individuals who experience mental distress are inherently 'disordered' alongside an internal dialogue which questions that belief, can result in perpetual and pervasive cognitive dissonance, as expressed by participants. In my interview with Jane, there were several times when she spoke about instances of self-doubt that were directly connected to her experience with the mental health system. Jane expressed skepticism about whether her experiences were actually meritful of the diagnosis she was given, "I just feel like some of these things that I go through like "normal” people go through them too." This statement captures the vagueness of diagnoses and diagnostic criteria. Many scholars have demonstrated the subjectivity in diagnoses, evidencing that there are numerous factors which influence one's likelihood of being given a particular diagnosis such as, race, gender, sex, age etcetera (Rimke, 2016; Lefrancois \& Diamond, 2014). These scholars have exhibited the subjectivity of diagnoses 
and have indirectly validated the doubts of individuals who question the diagnosis they were given.

All three participants spoke widely about the impact pathologization had on their selfperception and self-efficacy. Bailey explained that in her experience of psychiatrization, she was made to feel ashamed when she was not doing well. Bailey recalled being told; "get it together, what are you doing? You know you're not doing well.” Bailey articulated the influence this had on her self-perception following 'treatment',

I left that place feeling like it was my fault and my responsibility to like get over it and I felt inadequate because I was unable to live up to their treatment plan and I felt like I was failing.

What was most interesting about this is that earlier in the interview, Bailey expressed having little input in the decisions regarding her own treatment. Therefore, rather than questioning the treatments effectiveness, psychocentrism asserts that Bailey's ongoing experience of distress is a result of her own shortcomings, "I still struggle with feelings of incompetency that come directly from being told that I'm a sick person and being told that I'm never going to recover from this.” Jane, too, spoke of how her experience of psychiatrization has resulted in a prolonged sense of incapability, "that label has just hung over my head for so long and it's been a source of what I can and cannot do.” Furthermore, Cassandra spoke about the influence psychocentric interpretations of mental health had on their prospects for the future. Before applying and eventually being accepted into a Master’s program, Cassandra had to confront feelings of selfdoubt "I did not believe I was intelligent before that. I thought I was just a crazy person.” Cassandra explained that they felt unintelligent and 'crazy' because that is what was reinforced by 'psy' professionals and continues to be reinforced through widespread systemic sanism. 
I began to understand that my participants were not merely expressing a need to 'recover' from their experiences of emotional distress, but a need to 'recover' from their experience of the mental health system. For instance, Bailey described how she felt about her experience in retrospect, "I had to recover from this help that I was given in the same way that I learned to deal with eating issues or like anxiety or depression or other things in my life.” For all the participants in one way or another, I learned that their experiences had not only been negative, but resulted in a complete sense of distrust in the mental health system, mental health professionals, and for some, all helping professionals altogether. In response to a question about how this experience has made her feel about the mental health system, Bailey replied that her experience, "made me not want support. It made me not want support from the hospital or from a medical professional. It made me fearful to go and get support if I needed it.” This sentiment was shared by Jane, who when asked about her feelings about accessing services from mental health professionals, or 'head people' as she refers to them, Jane replied;

I don't want to see head people anymore like all of my experience with head people has been like so sh*tty and also and this may be off topic but it makes me feel like I can't call 911 when I'm in crisis.

This was an extremely powerful moment. I recognized that this experience for Jane was not just about the mental health system, but about coming to terms with the fact that services intended to support people are no longer seen as options for her. In the interview, Jane discussed a time where she had been treated poorly by a police officer amid a panic attack. Jane expressed frustration with the common suggestion that individuals in crisis should call 911 given that, "there so many different cases of people with mental illness being treated completely $\mathrm{f}^{* * * * *}$ up by the same people that are supposed to serve and protect so it's just like why? Why is that a 
thing?” Jane poignantly points out that even the ability to call 911 in a crisis, is a privilege not awarded to many.

\section{Identity}

One's identity is described as 'who or what a person or thing is', however the state of being, is not a simple concept (Oxford Dictionary, n.d.). Identity plays many functions in our lives. We use our identity to define ourselves, but our identity is also how we are defined by others. When an individual is diagnosed with a 'mental health disorder', they are provided with a label. These labels come with a wide range of stigmatizing connotations that intentionally or not, often become associated with an individual's identity. The dominance of psychocentric explanations for individual experiences are so prominent that these labels often go unquestioned, irrespective of the fact that they may not be warranted, desired, or helpful (Moses, 2009). As Cassandra explained; "that's the identity that I then had for myself because that's what they gave me and that's how they wanted to define me and I started to believe that.” However, in adulthood, it appeared that for all of the participants, identity was something they learned to often negotiate, strategically, depending on context.

Each participant had a different way of relating to the diagnosis they were given, however, when I asked participants how they identified in relation to their mental health, it became evident that the diagnoses were not something that they felt captured or accurately described how they experienced mental health. For instance, Jane spoke about feeling uncertain about how she would describe her mental health; "how I personally identify it? I'm not too sure. I mean there's a lot of flaws with the DSM, I believe, so I don't really know if I could put a label on it.” Jane's uncertainty speaks to both the feeling of lacking the language to accurately describe one's experiences caused by the dominance of psychocentric discourse, while also 
hinting to the messiness and ambiguity of mental health experiences. Likewise, Cassandra mentioned that within their circle of friends, they prefer to describe symptoms, rather than utilize psychiatric diagnoses;

I don't really identify with the label so usually with my friends we know that we just talk about symptomatology like, ‘that paranoid thing we do' or 'I feel anxious' but it's never associated with medication or the DSM 5 label.

Later in the interview, Cassandra spoke to the difficulty of describing experiences of mental health because of hegemonic psychocentrism and the subjugation of alternative ways of knowing, "it's a limitation of our language and I tried to convey those counter meanings through the language but even the language is built to propel the system.” As aforementioned within my theoretical framework, Mad Studies initially presented an exciting possibility to conceptualize mental health experiences outside of pathologizing discourse. However, its arguable complicity in the maintenance of white supremacy, has made this identity one of controversy for many. For this reason, I was interested in how my participants felt about 'Mad' identities as an alternative to psychiatric labels. Notably, Bailey was the only participant who mentioned the term 'Mad' prior to being asked,

I guess the language I use is probably not disorder like I'd probably say I struggle with mental health stuff; sometimes I'll say issues; sometimes I'll identify as a 'Mad' person although I'm thinking through that identity a bit more.

The very fact that Bailey was the only participant who felt comfortable identifying as 'Mad', supports the belief that 'Mad' may be an identity only available to individuals who are white. In follow up questions, I realized that Bailey had already come to this conclusion; 
The concept of madness is empowering in that it is me it and it is a politicized identity and a place to work and change from, but I'm struggling with that because how accessible is this concept to people? I don't know and I don't then know what it means for me to identify as this concept, if it's not actually an inclusive accessible meaningful term for everyone.

Bailey helped me to understand that adopting a 'Mad' identity indirectly reinforces the marginalization, exclusion and oppression of individuals with intersectional experiences of emotional distress. As someone who has previously identified as 'Mad', I too, am guilty of and implicated in this process. In discussing 'Mad' identities with Jane, she discussed feeling as though the identity was not only something she did not relate to, but that she did not believe would serve her in any way;

I feel like to be honest a lot of people within my social circle don't necessarily understand what 'Mad' or being 'Mad' is so if I were to say, 'oh I'm 'Mad' I feel like they don't quite get it and they may be like 'oh what's wrong?' and then it's like 'oh no I identify as 'Mad”' so it's difficult and depends on what kind of a context I'm in.

For Jane, identifying as 'Mad' did not feel like an identity that would be accepted or understood by her peers, as a result, the identity did not allow her to feel the same sense of empowerment that Bailey described. However, Jane did mention that her inclination to identify in certain ways is dependent on context. Cassandra, too, described a need to be strategic in how and when they would be able to utilize their 'Mad' identity,

I do identify as 'Mad' in some spaces, but when I do use 'Mad' it's when I'm trying to explain to my friends, but outside of that if someone was like, do you identify as 'Mad'? I would only say in certain contexts when it suits me, but in an authentic way. 
Both Cassandra and Jane highlight that they do not have the privilege of identifying as 'Mad', in the same way that Bailey does. Thus, even the ability to utilize counter-discourse, may be a privilege only available to those who are white. Cassandra discussed the ways in which they had to be strategic as to where and for what purpose they used certain identities, "I use all labels in specific circumstances in order to suit my needs.” Therefore, negotiating one’s identity is a

process that all participants underwent to some degree. For Bailey, this process involves recognizing the privilege of being able to choose how she identifies, while for Cassandra and Jane, this is a method of survival.

\section{Resistance}

There are various ways participants spoke about how they purposefully resist psychiatric discourse. A common strategy shared by all participants was seeking out likeminded others that can relate to and validate their experiences. Bailey described that for her;

It's extremely validating to know that people had not good experiences like I did. It was helpful to be like okay my anger in this situation is legitimate and not that I was just failing to do what they wanted me to do.

It seemed like for Bailey, connecting with individuals who shared similar experiences with the mental health system, reinforced her belief that her distress was not a matter of her own inadequacy, but a systemic inadequacy to effectively support individuals in distress. Similarly, Jane found comfort in spaces with others who offered her a nonjudgmental space to talk about her experiences;

there is a peer support group at [Undisclosed Location] that I was an associate of and going to those events and talking about my story and hearing people who have stories 
similar as me, I don't know it feels almost like they're standing in solidarity with me and it makes me feel like I'm not as alone as I used to be.

Likewise, Cassandra described that their community functions as a way of "legitimizing the 'crazy s***' that we're feeling as like a real response as rational people or just normal responses based on our individual lived experiences.” As Cassandra makes note of, what is considered 'normal' is not only subjective, but contextually and historically determined. Thus, what is considered a 'normal' response for one person may not be for another. These differences are inevitable based on the multiplicity of factors which encompass individual identities and prompts the question of why some behaviors are pathologized over others. To form communities with individuals who reject psychiatric discourse and the medical model approach represents resistance not only to pathologization but resistance to determinism and individualism ingrained within psychocentrism. The very act of sharing experiences with others is resistant to notions that 'mental illness' is biological because it demonstrates that experiences of distress are not necessarily unique or 'disordered', but life experiences shared by many. Further, these communities serve to trouble notions of pathological individualism which views people in terms of ab/normalcy.

Supplementary to that, Cassandra spoke about the influence this experience has had on their life in adulthood. "I see that a lot of these issues that I may be going through might be a resultant of this oppressive society that I live in.” Here, Cassandra explains that their experiences are conflated with those of institutional racism, classism, heterosexism etcetera. When talking about their decision to enter their field of study, Cassandra explained, “I don't even think I knew what critical disability studies was before I got into it, I just knew that I wanted to talk about my 
experience”. This decision prompted an opportunity for Cassandra to view their experiences differently;

I felt like a victim but I didn't know that I was a survivor of something or felt like a psychiatric survivor because I didn't know that language and I didn't know how to mobilize until that academic scene and that's privilege.

Once they had entered academia, Cassandra was introduced to concepts of anti-psychiatry and learned about consumer-survivor movements. As aforementioned, these spaces present exciting opportunities for conceptualizing mental health devoid of pathologization, however, as Cassandra mentions, these spaces are still inaccessible to the general public and thus, remain as sites of privilege and oppression. Cassandra spoke widely about their passion for working to challenge the psychiatric system on a larger scale and is engaged in advocacy to help others in their fight against pathological individualism and institutional sanism. They state that their experience of the mental health system "has directed my academic work and personal advocacy. I'm dedicated to speaking out against the reliance of psychiatry in our society.” When I asked Cassandra what drives their activism, they replied;

It comes from this deep sense of loss that I and many of my friends who are also activists in this area understand which is that we are psychiatric survivors and we didn't know any other options at the time. And I personally want to help others avoid being forced to define themselves in that way.

It is hard to deny that a system needs to be questioned, when individuals who were supposed to be supported by that system, dedicate their lives to dismantling it. From all three participant accounts, it is evident that their experiences with the mental health system in adolescence, have had critical impacts on their lives and livelihood in adulthood. This presents a very scary reality. 
The ability for psychocentric discourse to shape and influence not just an individual's view on themselves, but society's view of that individual, arguably demonstrates an active form of social control that is shaping how we understand, conceptualize and think about behaviour. In her final thoughts, Jane wonders, "if I never got diagnosed in the first place I probably would be a very different person than I am right now.” This statement I found to be most telling, as it suggests that individuals who have been psychiatrized in adolescence have been denied the opportunity to become who they would be if they had never been deemed 'disordered.' 


\section{CHAPTER 6. DISCUSSION}

This research process has been undeniably the greatest learning experience of my academic career. What began as an intent to explore a topic that interested me, became an interrogation of everything I thought I knew about myself as an academic, as a professional and as a researcher. When I started this research, I proposed to explore, not one but two research questions. I knew I wanted to study retroactive accounts of experiences of madness and that desire prompted my first research question. However, as a student of a school which prides itself on a commitment to anti-oppression, I was aware that experiences of sanism often conflate with experiences of racism, classism, heteronormativity etcetera. Therefore, I knew that I wanted to explore these experiences as well, after all, I thought that is what a good anti-racist social justice worker would do. This is what prompted my initial decision to use Critical Mad Perspectives as my theoretical framework, as well as, my second research question, which was 'how do individual experiences of madness differ based on intersecting identities?'

My intention was to bring attention to those intersections by highlighting the increased susceptibility of individuals with intersectional identities to be pathologized. However, in spite of my social justice orientation, I found myself replicating structures of white supremacy within my research. I began questioning all aspects of my research from theory to methodology. The more I questioned, the more critical I became and the more I criticized, the more I came to discover that I was in fact reinforcing that which I was struggling to confront. I became the well-intentioned white researcher who I was forewarned to be wary of.

In learning more about Anti-Racism and Anti-Colonialism theory, I became more conscious of my own participation in the construction of the subject positions of others. If I were to recruit participants on the basis of having intersectional or marginalized identities, I would 
have set up binaries of research/researched, white/Black, queer/heterosexual, and in doing so, would contribute to a fixing and essentializing of identities. Furthermore, the very premise of the question is based on the assumption that a unitary experience of oppression exists which reinscribes individuals into homogenous groups and denies the heterogeneity of individual experiences. This recognition along with my decision to change my theoretical framework, helped me to see that not only could I not ethically or responsibly answer my second research question, but that I needed to change the way I approached the research process entirely.

There are numerous limitations with this study, beginning with my research design. My eligibility criteria presented a limitation to my study which I had not originally intended. Throughout my recruitment process, I realized that the majority of recruitments who were eligible for the study were white. This made me wonder about the inclusivity of my eligibility criteria. I believed that by allowing participants to self-define what is considered as 'experience with the mental health system', I was allowing for a wide range of experiences to be eligible. What I noticed, however, is that by stating that the experience had to be with the mental health system, I prevented anyone with an experience of madness, psychiatrization or pathologization outside of the mental health system from participating in the study. Sanist and psychocentric discourses extend far beyond the formal mental health system including the educational, criminal justice and legal systems. This limitation substantially influenced the scope of the study as it prevented any exploration of the influences sanism and psychocentrism has on individuals who did not have experience with the formal mental health system as an adolescent. It is my belief that a wider eligibility criteria would have allowed for greater diversity within the experiences of emotional distress presented in this study. 
This study is also limited by the size of my recruitment sample. It would not be possible to generalize the findings of this data as three participants are not sufficient to draw conclusions that would be representative of a larger population. The study is additionally limited by the fact that all the participants are either university students or graduates. I believe this is attributed to the influence that my positionality had on the research design, but also the subjugation of knowledges alternative to psychiatry. I began to wonder whether even the ability to critique psychocentrism is a privilege only available to those who have been exposed to counterdiscourses found within academia.

I also found that time was a limitation to this study. I originally proposed to conduct member checking, whereby I would return transcripts from the interviews to my participants to receive their feedback around how they would like to be represented. However, after needing to re-think various aspects of my research, I found myself rushing to meet the deadline. This prevented me from having the time necessary to offer my participants an opportunity to review the interview transcripts.

The last limitation which I will discuss, is myself as the researcher. As a white, cis, heterosexual woman, Yancy (2012) has helped me to realize that no matter how attuned I become to recognizing internalized racism, there is no absolute epistemic clarity that can be achieved as true objectivity is not possible. Therefore, notwithstanding my capacity for introspection, I have learned the importance of tarrying with the reality of my embeddedness in white supremacy and accept that there are inherent limitations to my interpretations of this data based on my identity and worldview.

Cassandra, Bailey and Jane, each shared rich accounts of their experiences as adults who have been influenced by psychocentrism. As discussed in my literature review, the drastic 
increase in pathologizing behavior simultaneous with the booming of the pharmaceutical industry is a coincidence that cannot be ignored. Each participant discussed a multiplicity of events occurring in their lives in tandem to their experiences with the mental health system, yet, the resounding messages provided by 'psy' experts is that participant struggles were strictly personal and separate from the social context within which their experiences are embedded. What is evident from this research, is that experiences of psychocentrism impact individuals long after their involvement with the mental health system has ceased. My research participants highlight a process of learning how to understand ourselves outside of the understanding that has been imposed upon us that persists well into adulthood. These experiences demonstrate a strong likelihood that individuals who have been subjected to the mental health system as an adolescent, will find themselves questioning their self-perception, identity, and worldview in adulthood. Therefore, I believe that psychocentrism must be closely examined as a form of social injustice and ongoing colonialism. 


\section{CHAPTER 7. IMPLICATIONS}

The findings from this study, guided by an Anti-Colonial, Anti-Racist and Mad Studies lens, have highlighted two important implications for social work practitioners. The first is around madness as an active colonial project and the second is around white researchers with anti-racist research objectives. When I began this research, I already knew that mainstream mental health care based on psychocentric knowledge was not working to challenge sanism, racism, colonialism or oppression. Thus, I will not reiterate those findings here. Rather, I will highlight the biggest takeaways from this research process.

\section{Madness as a colonial project?}

Through this research project I have come to understand that the use of Mad Studies is not as progressive or social justice oriented as I originally thought. Mad Studies emerged from the need to explore counter-discourses and alternative ways of knowing, however, I do not believe that it ever did or could achieve that objective within a Eurocentric epistemology. As aforementioned in this work, the Mad movement came into being in response to the advancing power of psychiatry (Menzies, et al., 2013). However, like other activist movements, such as the first wave-feminist movement, it did not consider an intersectional lens (Fernando, 1995). Therefore, experiences of madness were explored independent of various other social processes of racism, criminalization, heteronormativity and white supremacy. Without attention to colonization, Mad Studies participates in the ongoing violence within Eurocentric knowledge production. Further, the notion of 'Mad Pride' which Mad Studies encourages is also problematic for various reasons. Firstly, the notion that someone can feel a sense of pride about their experiences of madness assumes that those who have been deemed 'Mad' by society, personally identify with having an experience of madness. As has been discussed earlier, many 
individuals who have experience with the mental health system do not believe that there is anything 'Mad' about them.

Within Mad Studies scholarship, this research included, I have realized that to refer to individuals as 'Mad', not only denies their agency to self-define their experiences, but reinforces their position as 'othered' even within a counter discourse. My participants, particularly Cassandra and Jane, illustrated that not everyone wants to or can identify as 'Mad.' As people with visibly intersectional identities, they remind me that it is not only a privilege to be able to claim this identity but also an identity that has been monopolized by white people. Secondly, the notion that one can feel a sense of 'pride' in their experiences, is also problematic. The idea of 'pride' is associated with a celebration of difference and individuality. That idea, although perhaps seemingly an act of resistance, does nothing to challenge pathological individualism or determinism, but merely challenges the idea that these experiences are negative. Furthermore, survivor groups are predominantly influenced by a white Western value system. A common aim of consumer/survivor movements is to empower individuals to re-gain control of their lives (Fernando, 1995). For someone with Western beliefs, control is seen to be achievable from an individual stance and often separate from culture, society and environment (Fernando, 1995). This objective is completely negligent of various other social processes of oppression which exist within and outside of the consumer/survivor movement and allow those within the movement to forgo the ways in which they themselves are implicated in these processes. As Diamond (2013) asserts, “essentializing mad discourse and psychiatric discourse has the potential to obscure how processes of racialization, gender, class, disability, sexuality and other processes shape and define madness.” Thirdly, Mad Studies and Mad movements often fail to consider that different groups of people are accorded varying amounts of power depending on 
their race, culture and class. This reality has significant implications for potential involvement as the consequences of speaking out against psychiatric discourse will differ based on individual social location. For instance, the fact that African-Caribbean people are disproportionately more likely to be sectioned under the Mental Health Act, presents extremely different risks for someone to become involved in consumer/survivor movements and makes notions of celebrating 'Mad pride' not only inaccessible but dangerous (Fernando, 1995). For these reasons, I have come to understand Mad Studies and Mad movements as colonial projects that reinforce Western ideologies and white supremacy through their strive to make their voices heard, albeit

unwittingly, at the expense of silencing others. Moving forward, I have learned that Mad Studies is at the very least insufficient to explore intersectional experiences of distress, and forewarn future researchers of utilizing Mad Studies without situating knowledge within a colonial context. As an alternative to Mad Studies, I encourage the use of anti-sanism as a theoretical lens by which experiences of emotional distress can better be explored in tandem with colonialism and white supremacy.

White researchers and the strive to be 'anti-racist'

Research has always been deeply implicated within the oppression of marginalized groups (Bishop, 2005, as cited in, Chadderton, 2012). Research has represented a means to 'objectify, exploit and dominate marginalized groups' through misrepresentation and the maintenance of oppressive social structures (Delgado Bernal, 1998, as cited in, Chadderton, 2013). White researchers, like myself, have spoken for and about people from other ethnic groups and have contributed to the silencing of marginalized voices. It can be argued, that all research is exploitative in nature as it most often serves the interests of the researcher, rather than those of the researched (Kvale, 2006, as cited in Chadderton, 2012). With that said, I am not 
ready to concede to the notion that white researchers have no place in researching topics of race and/or racism as leaving the study of race to those who are racialized not only poses the risk of further marginalizing those groups, but would also make racism a minority problem. However, this research process has forced me to recognize the complexities and tensions of being a white researcher with anti-racist research objectives. In the Declaration of Whiteness, Ahmed (2004), explains how declarations of white complicity must be interrogated. While seemingly wellintentioned, for a white person to state 'I am racist' does less to assert one's racism than it does imply the opposite, 'I am not racist'. Ahmed helped me to understand that to simply state my complicity in White supremacy, is not only counterintuitive but counterproductive. I have come to realize that by confessing my whiteness, I eliminate what has caused my discomfort of learning about complicity and once again, positions myself as innocent in matters of race and racism. Equally problematic, is the strive to be anti-racist, as Ahmed (2007) explains that the desire to act in non-racist or anti-racist way when one hears about racism, in my view, can function as a defense against hearing how that racism implicates white subjects, in the sense the it shapes the spaces inhabited by white subjects in the unfinished present. As a white researcher, I no longer think it would ever be possible to conduct research that is not in any way somewhat racist. Applebaum (2013), opened my eyes to the need for white antiracists to be vigilant in matters of complicity. Vigilance involves a watchfulness and sense of alertness against some form of danger. Yancy (2008) describes that vigilance is necessary because whiteness is "deferred by the sheer complexity of the fact that one is never selftransparent, that one is ensconced within structural and material power racial hierarchies.” Therefore, even with an honest effort to resist enacting my whiteness within this work, I found myself doing just that. My ability to critically reflect upon and move forward with my research, 
is a result of accepting that I am "unavoidably part of something that is doing something in me, for me, through me, as me” (Boyd, 1997, as cited in, Applebaum, 2013). In other words, I now understand white complicity as the awareness that I cannot transcend the system that has constructed how I make meaning of myself and the world around me. Moreover, I have learned the futility of striving to be anti-racist as,

the white self that attempts to ascertain such limits has already arrived too late to determine the complex and insidious ways in which white racism has become embedded within her white embodied self. It is not that there is no transparency at all, that one is incapable of identifying various aspects of one's racist/nonracist white self. Rather, the reality of the sheer depth of white racialization is far too opaque (Yancy, 2012).

This teaching has challenged me to stay in my discomfort throughout the completion of this work in attempt to remain vigilant. Moving forward, I encourage white researchers to not strive to be anti-racist, but to challenge white supremacy by remaining in spaces of complicity, discomfort and embeddedness, for it is within those spaces, that I believe new learning is most likely to occur. 


\section{CHAPTER 8. CONCLUSION}

It is hoped that this study in some ways adds to the conversation about the significant influences psychocentric adolescent mental health care has on individuals in adulthood, and the importance of understanding their intersections with social processes of marginalization and oppression. Specific to social work, I hope that this study incites a consideration of anti-sanism as opposed to Mad Studies as a counter-discourse to psychocentrism. As I came to the completion of my paper, I found humour in recognizing that the MRP process is in itself psychocentric and individualistic in nature. Thus, even as I write to challenge these processes, I am simultaneously reinforcing them. Furthermore, my intention of completing this research for the purpose of achieving a graduate degree is also completely intertwined with whiteness and colonialism. I have come to recognize that as a white academic and social worker, I will always be in a position that is perpetually reinforcing white supremacy, regardless of my attempts to do otherwise. I also hope to have inspired future graduate students to dig deeper in their exploration of the ways in which they themselves are implicated and embedded within their work As I move forward in my social work practice, I will remain vigilant in my attempt to address white complicity and be cognizant of how efforts to be anti-racist move me away from my responsibility to "tarry with my opaque white racist self" (Yancy, 2012). 


\section{APPENDIX}

Appendix A- Interview Guide

1. What is your age or age range?

2. How would you identify yourself in tersms of ethnicity?

3. How would you identify yourself in terms of gender?

4. How would you identify yourself in terms of sexual orientation?

5. What prompted you to decide to become involved in this study?

6. How do you currently identify in relation to your mental health? (mad, mental health consumer, mental health challenged, mental diagnoses, mentally ill etc.)

7. Describe yourself as an adolescent.

8. Tell me about your first encounter the mental health or psychiatric system?

o How did you first come into contact with the system?

o What was that experience like for you?

o Was a diagnosis provided at this time? If so, how did you feel about the diagnosis?

o Were there any external factors occurring simultaneously? i.e. problems at school

o How did you cope with the experience?

9. Did you have an ongoing relationship with the system? If so, please tell me about the relationship i.e. were you a recipient of mental health treatment, medication, counselling etc.

10. How did you feel about the relationship? Was it positive or negative? Please explain.

11. Did you feel that your thoughts and opinions were taken into consideration?

12. How would you describe your relationship with friends and/or family during this time?

13. How would you describe your relationship with yourself during this time?

14. How did your relationship with the system come to end?

15. Did you experience any repercussions following the termination?

16. Looking back at this experience, how do you currently understand it?

17. What do you think the biggest impacts of this experience may have been?

18. Have you spoken to others who have also experience with the psychiatric system as an adolescent? If so, how do you think your experience compares to others?

19. What are your current thoughts on the psychiatric system?

20. How would you currently describe your relationship with your mental health?

21. How do you feel now, after having just reflected on this experience? 


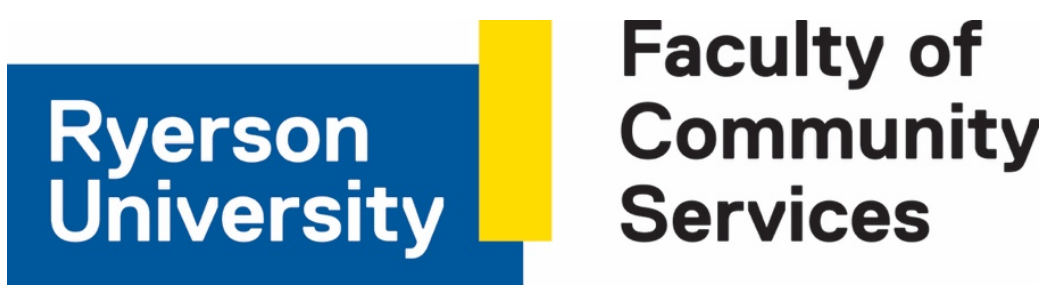

My name is Jordana Rovet. I am a student at Ryerson University in the School of Social Work. I am grateful for your potential interest in participating in this research study and would like to take this opportunity to tell you more about it.

This research is being done to complete the major research paper requirement of my Master of Social Work degree and my supervisor's name is Gordon Pon, Associate Professor at Ryerson. The focus of the research is to explore how individuals understand their experience of adolescent psychiatry in adulthood.

To participate you need to identify as having experience with the mental health system during adolescence, are over the age of 18 and do not currently identify as a recipient of psychiatric care. Participants will also be selected based on intersectional experiences of race, ethnicity, gender and/or sexual orientation.

If you agree to volunteer, you will be asked to you will be asked to participate in a one-on-one interview with myself for approximately 1.5-2 hours.

In appreciation of your time, you will receive reimbursement for any travel expenses, as well as, a beverage and snack of your preference at the time of the interview.

Your participation is completely voluntary and if you choose not to participate it will not impact our relationship or your relationship with Ryerson University.

The research has been reviewed and approved by the Ryerson University Research Ethics Board.

If you have any questions about the research now, please don't hesitate to ask. If you have questions later about the research, you may contact myself at jordana.rovet@ryerson.ca and/or Gordon Pon at g2pon@ryerson.ca, Tel: 416-979-5000, Ext. 4786. 


\section{Ryerson
University \\ Faculty of Community Services}

\section{Ryerson University Consent Agreement}

You are being invited to participate in a research study. Please read this consent form so that you understand what your participation will involve. Before you consent to participate, please ask any questions to be sure you understand what your participation will involve.

\section{PSYCHIATRY LEAVING A QUESTION MARK}

INVESTIGATORS: This research study is being conducted by Jordana Rovet, a graduate student in the Master of Social Work Program, under the direct supervision of Dr. Gordon Pon.

If you have any questions or concerns about the research, please feel free to contact Jordana Rovet at jordana.rovet@ryerson.ca.

PURPOSE OF THE STUDY: This study will explore how individuals understand their experience of adolescent psychiatry in adulthood. Using a qualitative research design, I will interview 3-5 individuals, over the age of 18, who identify as having experience with the mental health system during adolescence but who no longer identify as having a connection with the system. Participants will be selected based on their social location and positionality to allow for a diverse research sample. In interviewing this demographic, I hope to distinguish important perspectives of how these individuals understand their experience of psychocentrism within the mental health system. These understandings will also be looked at in relation to individual experiences of intersectionality. I am completing this research to complete the major research paper requirement of my Master of Social Work degree (expected completion of program August 2017).

WHAT YOU WILL BE ASKED TO DO [OR] WHAT PARTICIPATION MEANS: If you volunteer to participate in this study, you will be asked to do the following things:

- Correspond with the researcher to schedule an interview.

- Participate in a one-on-one interview with the researcher for approximately 1-2 hours

- Participant will be asked questions related to their experiences of receiving psychiatric services in adolescence, as well as, the influence this experience may have had on one's life as understood in adulthood.

- Participant will be asked to provide the following demographic data; name, age, ethnicity, gender identity and sexual orientation. All identifying information will be kept 
confidential. The information will be kept confidential and securely stored electronically with password protection - it will all be destroyed prior to publication. None of this information will ever be used in the research publication where, instead, pseudonyms will replace the names.

- Participants will be provided the opportunity to review the transcripts of their interviews to evaluate accuracy and acceptability of their contributions. The interview transcripts will be provided to participants within one month following the time of their interview and participants will be asked to return their comments within a 10-day period.

- A copy of the final paper will be made available to participants through an electronic method of their preference i.e. email or USB upon request.

POTENTIAL BENEFITS: Participants may not gain any direct benefit from participating in the study. However, study findings will contribute to the literature on experiences of adolescent psychiatry and may prompt interest for future research on this subject.

WHAT ARE THE POTENTIAL RISKS TO YOU AS A PARTICIPANT: Due to the personal nature of the questions asked, a participant may reflect on unpleasant memories during the interview. Participants will be reminded that they can skip questions, take a break, or discontinue the interview permanently as well as withdraw from the study at any time. Counselling services will be made available to all participants. After the interview, the researcher will again check-in with the participant and offer information about how to access support services. The researcher will also offer the participant a follow-up call the next day, as well as, advise the participant that they can contact the researcher at any time for information about accessing support services.

CONFIDENTIALITY: No personal information of identity will ever be included in the completed research publication. All demographic data will be stored securely in password protected files. Signed consent forms, audio recorded interviews, interview transcriptions, and contact information (names, email or phone number) will be collected. All digital data will be stored electronically under password protected files solely in the researcher's computer. Signed consent forms will be kept in a secure locker which is kept in a secure room only accessible to other Social Work masters' students. All data will only ever be kept by the single researcher Jordana Rovet.

The audio recordings will be password protected on the audio device and uploaded to password protected audio files. These audio files will be deleted once the transcriptions are completed which is anticipated to be within a week of the interview being audio-recorded. At this point, the transcriptions will be kept as password protected files up until the final draft of the paper is completed and submitted to the School of Social Work of Ryerson University - this is anticipated for mid-August 2017. Once the paper is submitted to the School of Social Work of Ryerson University the transcriptions will be destroyed. The transcriptions are only kept until final publication so that I can review them and write my paper.

Participants will be asked to review/edit their interview transcripts as well as edit/approve the final research paper to ensure they are comfortable that the information does not identify them to potential readers. Pseudonyms will be used in the publication. 
INCENTIVES FOR PARTICIPATION: Participants of the study will be provided with a coffee or alternative beverage and a snack of their choice at the time of their interview. Participants will not be paid to participate in the study.

COSTS TO PARTICIPATION: The only potential cost associated with participation is transportation. TTC tokens will be reimbursed to participants for transportation expenses.

VOLUNTARY PARTICIPATION AND WITHDRAWAL: Participation in this study is completely voluntary. You can choose whether to be in this study or not. If any question makes you uncomfortable, you can skip that question. You may stop participating at any time and you will still be given the incentives and reimbursements described above. If you choose to stop participating, you may also choose to not have your data included in the study. Your choice of whether to participate will not influence your future relations with Ryerson University or the investigator, Jordana Rovet, involved in the research.

QUESTIONS ABOUT THE STUDY: If you have any questions about the research now, please ask. If you have questions later about the research, you may contact Jordana Rovet at jordana.rovet@ryerson.ca and/or Gordon Pon at g2pon@ryerson.ca

This study has been reviewed by the Ryerson University Research Ethics Board. If you have questions regarding your rights as a participant in this study, please contact:

Research Ethics Board

c/o Office of the Vice President, Research and Innovation

Ryerson University

350 Victoria Street

Toronto, ON M5B 2K3

416-979-5042

rebchair@ryerson.ca 


\section{REFERENCE LIST}

Abdillahi, I., Meerai, S., \& Poole, J. (2017). When the suffering is compounded: Towards antiblack sanism. In S. Wehbi \& H. Prada (Eds.), Reimagining anti-oppression social work practice. Canadian Scholars Press.

Ahmed, S. (2007) A phenomenology of whiteness. Feminist Theory, 8(2), 149-168.

Ahmed, S. (2004) Declarations of whiteness: The non-performativity of anti-racism. Borderlands E-Journal, 3(2).

American Psychiatric Association. (2017). DSM-5 FAQ. Retrieved May 21, 2017, from https://www.psychiatry.org/psychiatrists/practice/feedback-and-questions/frequently-askedquestions.

Applebaum, B. (2013). Vigilance as a response to white complicity. Educational Theory, 63(1), $17-34$.

Birnbaum, M. (1960). The right to treatment. American Bar Association Journal, 46(5), 499_ 505. Retrieved from https://www.jstor.org/stable/25721181?seq=1\#page_scan_tab_contents

Bluhm, R. L., Covin, R., Chow, M., Wrath, A., \& Osuch, E. A. (2014). "I just have to stick with it and it'll work”: Experiences of adolescents and young adults with mental health concerns. Community Mental Health Journal, 50(7), 778-786. https://doi.org/10.1007/s10597-0149695-X

Breggin, P. (1991). Toxic psychiatry: Why therapy, empathy and love must replace the drugs, electroshock, and biochemical theories of the “new psychiatry.” New York: Martin’s Press. 
Breggin, P. (2014). The rights of children and parents in regard to children receiving psychiatric diagnoses and drugs. Children \& Society, 28, 231-241.

Carter, P. L. (2014). "Black” cultural capital, status positioning, and schooling conflicts for lowincome African American youth. Social Problems, 1, 136. https://doi.org/10.1525/sp.2007.54.1.23.

Chadderton, C. (2012). Problematising the role of the white researcher in social justice research. Ethnography and Education, 7(3), 363-380.

Chase, S. E. (2003). Learning to listen: Narrative principles in a qualitative research methods course. Up Close and Personal: The Teaching and Learning of Narrative Research., 79-99. https://doi.org/10.1037/10486-005

Chilisa, B. (2012). Situating knowledge systems. In Indigenous research methodologies (pp. 144). Thousand Oaks, CA: SAGE Publications Ltd.

Constantine, M. G. (2007). Racial microaggressions against African American clients in crossracial counseling relationships. Journal of Counseling Psychology, 54(1), 1-16. https://doi.org/10.1037/0022-0167.54.1.1

Coppock, V. (2004). "Mad”, “bad” or misunderstood? In P. Scraton (Ed.), Childhood in Crisis? (pp. 146 - 161). London: Routledge. Retrieved from http://lib.myilibrary.com/Open.aspx?id=32465

Costa, L. (2013). Mad patients as legal intervenors in court. In B. Lefrancois, R. Menzies, \& G. Reaume (Eds.), Mad matters: A critical reader in Canadian mad studies (pp. 195-209). 
Toronto: Canadian Scholars’ Press Inc. Retrieved from https://www.amazon.ca/MadMatters-Patients-Legal-Intervenors-ebook/dp/B00I46TMJ2

Creswell, J. W. (2013). Qualitative inquiry and research design: Choosing among five approaches. SAGE Publications. Retrieved from http://catalogue.library.ryerson.ca/record=b2510757

Didyk, L. A. (2014). Centering sanism: Stories \& visions for mad-positive mental health. Unpublished Major Research Paper. Toronto: Ryerson University, School of Social Work.

Diamond, S. (2013). What makes us a community? Reflections on building solidarity in antisanist praxis. In B. A. LeFrançois, R. Menzies, \& G. Reaume (Eds.), Mad Matters: A Critical Reader in Canadian Mad Studies (pp. 64-78). Toronto, ON: Canadian Scholars’ Press Inc.

Fanon, F. (1968). Black skin, white masks. New York: Grove Press.

Fernando, S. (1995). Mental health in a multi-ethnic society: A multi-disciplinary handbook. New York, NY: Routledge.

Fernando, S. (2010). Mental health, race and culture. New York, NY: Palgrave Macmillan.

Foucault, M. (1954). Mental illness and psychology. Berkeley, CA: University of California Press.

Frances, A., \& Clarkin, J. (1981). No treatment as the prescription of choice. Arch Gen Psychiatry, 38(5), 542-545. 
Fricker, M. (2007). Epistemic Injustice. Oxford: Oxford University Press. https://doi.org/10.1093/acprof:oso/9780198237907.001.0001

Goffman, E. (1963). Stigma: Notes on the management of spoiled identity. Englewood Cliffs, N.J.: Simon \& Schuster Inc.

Gonzales, L., Davidoff, K. C., Nadal, K. L., Yanos, P. T., Gonzales, L., Davidoff, K. C., ... Yanos, P. T. (2014). Microaggressions experienced by persons with mental illnesses: An exploratory study. Psychiatric Rehabilitation Journal.

Gorman, R. (2013). Mad nation? Thinking through race, class, and mad identity politics. In B. Lefrancois, R. Menzies, \& G. Reaume (Eds.), Mad Matters: A Critical Reader in Canadian Mad Studies (pp. 269-280). Toronto, ON: Canadian Scholars’ Press Inc.

Gossage, H. (1966). Understanding Marshall McLuhan. Ramparts, 4(12), 34-37.

Haynes, C., Eivors, A., \& Crossley, J. (2011). “Living in an alternative reality”: Adolescents’ experiences of psychiatric inpatient care. Child and Adolescent Mental Health, 16(3), 150157. https://doi.org/10.1111/j.1475-3588.2011.00598.x

Holley, L. C., Tavassoli, K. Y., \& Stromwall, L. K. (2016). Mental illness discrimination in mental health treatment programs: Intersections of race, ethnicity, and sexual orientation. Community Mental Health Journal, 53, 311-322. https://doi.org/10.1007/s10597-016-99909

Hook, D. (2007). Governmentality and technologies of subjectivity. In Critical Psychology (pp. 239-271). Cape Town, South Africa: University of Cape Town Press. 
Lather, P. (1991). Getting smart: Feminist research and pedagogy with/in the postmodern. New York and London: Routledge.

Lavallee, L. F., \& Poole, J. M. (2010). Beyond recovery: Colonization, health and healing for indigenous people in Canada. International Journal of Mental Health and Addiction, 8(2), 271-281. https://doi.org/10.1007/s11469-009-9239-8

LeFrancois, B. (2006). They will find us and infect our bodies: The views of adolescent inpatients taking psychiatric medication. Radical Psychology, 5. Retrieved from http://www.radicalpsychology.org/vol5/LeFrancois.html

Lefrançois, B. A. (2008). “It’s like mental torture”: Participation and mental health services. International Journal of Children’s Rights, 16, 211-227. https://doi.org/10.1163/157181808X301809

Lefrançois, B. A. (2014). Queering child and adolescent mental health services: The subversion of heteronormativity in practice. Children and Society, 27(1), 1-12. https://doi.org/10.1111/j.1099-0860.2011.00371.x

LeFrançois, B., Menzies, R., \& Reaume, G. (2013). Mad matters: A critical reader in Canadian mad studies. Canadian Scholars’ Press.

Lincoln, Y. S., \& Guba, E. G. (1985). Naturalistic inquiry. Sage Publications. Retrieved from http://catalogue.library.ryerson.ca/record=b1000985 
Lindsey, M. a, Korr, W. S., Broitman, M., Bone, L., Green, A., \& Leaf, P. J. (2006). Helpseeking behaviors and depression among African American adolescent boys. The Social Worker, 51, 49-58. https://doi.org/10.1093/sw/51.1.49

Livingston, J. D., \& Boyd, J. E. (2010). Correlates and consequences of internalized stigma for people living with mental illness: A systematic review and meta-analysis. Social Science and Medicine, 71(12), 2150-2161. https://doi.org/10.1016/j.socscimed.2010.09.030

Menzies, R., LeFrancois, B. A., \& Reaume, G. (2013). Introducing mad studies. In B. Lefrancois, R. Menzies, \& G. Reaume (Eds.), Mad Matters: A Critical Reader in Canadian Mad Studies (pp. 1-22). Toronto: Canadian Scholars’ Press.

Moses, T. (2009). Self-labeling and its effects among adolescents diagnosed with mental disorders. Social Science and Medicine, 68(3), 570-578.

Offord, A., Turner, H., \& Cooper, M. (2006). Adolescent inpatient treatment for anorexia nervosa: A qualitative study exploring young adults’ retrospective views of treatment and discharge. European Eating Disorders Review, 14(6), 377-387.

Perlin, M. L. (1993). The ADA and persons with mental disabilities: Can sanist attitudes be undone. Journal of Law and Health Law Journals J.L. \& Health, 15. Retrieved from http://engagedscholarship.csuohio.edu/jlh

Pon, G., Giwa, S., \& Razacks, N. (2016). Foundations of anti-racism and anti-oppression in social work practice. In A. Al-Krenawi, J. R. Graham, \& N. Habibov (Eds.), Diversity and Social Work in Canada (pp. 38-58). Oxford University Press. 
Pon, G., Gosine, K., \& Phillips, D. (2011). Immediate response: Addressing anti-Native and antiBlack racism in child welfare. International Journal of Child, Youth and Family Studies, 385-409.

Poole, J. (2011). Behind the rhetoric: mental health recovery in Ontario. Winnipeg: Fernwood Publishing.

Poole, J. M., Jivraj, T., Arslanian, A., Bellows, K., Chiasson S., Hakimy, H....Reid, J. (2012). Sanism, "mental health”, and social work/education: A review and call to action. Intersectionalities: A Global Journal of Social Work Analysis, Research, Policy, and Practice, 1(1), 20-36.

Pinfold, V., \& Byrne, P. (2005). Challenging Stigma and Discrimination in Communities: A Focus Group Study Identifying UK Mental Health Service Users’ Main Campaign Priorities. International Journal of Social Psychiatry, 51(2), 128-138.

Poole, J. M., Jivraj, T., Arslanian, A., Bellows, K., Chiasson, S., Hakimy, H., ... Reid, J. (2012). Sanism, "mental health", and social work/education: A review and call to action. Intersectionalities: A Global Journal of Social Work Analysis, Research, Polity, and Practice, 1(1), 20-36. https://doi.org/1925-1270

Rimke, H. (1997). (Re)constructing the ethical self: Self-help literature as a contemporary project of moral regulation. Dissertation. Ottawa: Carleton University, Department of Sociology and Anthropology. 
Rimke, H. (2016). Mental and emotional distress as a social justice issue: Beyond psychocentrism. Studies in Social Justice, 10(1), 4-17.

Salamone-Violi, G. M. L., Chur-Hansen, A., \& Winefield, H. R. (2015). “I don’t want to be here but I feel safe': Referral and admission to a child and adolescent psychiatric inpatient unit: The young person’s perspective. International Journal of Mental Health Nursing, 24(6), 569-576. https://doi.org/10.1111/inm.12163

Surko, M., Ciro, D., Blackwood, C., Nembhard, M., \& Peake, K. (2005). Experience of racism as a correlate of developmental and health outcomes among urban adolescent mental health clients. Social Work in Mental Health, 3(3), 235-260.

Szasz, T. S. (1979). Critical reflections on child psychiatry. Children and Youth Services Review, $1,7-29$.

Thompson, R., Dancy, B. L., Wiley, T. R. A., Perry, S. P., \& Najdowski, C. J. (2011). The experience of mental health service use for African American mothers and youth. Issues in Mental Health Nursing, 32, 678-686. https://doi.org/10.3109/01612840.2011.595534

Timimi, S. (2006). Critical child psychiatry. In D. B. Double (Ed.), Critical psychiatry: The limits of madness (pp. 189-206). New York: Palgrave Macmillan.

Tucker, C. (2009). Low-income African American caregivers' experiences of being referred to mental health services by the school counselor: Implications for best practices. Professional School Counseling, 12(3), 240-252. 
Willis, J. (2007). Foundations of qualitative research: Interpretive and critical approaches., Thousand Oaks California: SAGE Publications, Inc. https://doi.org/10.4135/9781452230108

Wisdom, J. P., \& Green, C. A. (2004). "Being in a funk”: Teens’ efforts to understand their depressive experiences. Qualitative Health Research, 14(9), 1227-1238. https://doi.org/10.1177/1049732304268657

Yancy, G. (2012). Looking at whiteness: Tarrying with the embedded and opaque white racist self. In Look, a white! Temple University Press.

Identity (n.d.). Retrieved from https://en.oxforddictionaries.com/definition/identity 


\section{GLOSSARY}

\section{Consumer/Survivor:}

A term used to encompass both those who have received psychiatric treatment voluntarily and those who have had it forced upon them.

\section{Eurocentrism:}

A discursive tendency to interpret the histories and cultures of non-European societies from a European (or Western) perspective, with an implied belief, either consciously or subconsciously, in the pre-eminence of European culture.

\section{Madness:}

A ubiquitous term for a range of phenomena (e.g. violence, extremity, creativity, excellence, chaos) historically used in the West to indicate irrationality, confusion or distress in a situation or individual (e.g. mania, melancholy, lunacy). Madness discourse was formulated into psycho-medical terms (e.g. psychosis, depression, asociality) and psycho-legal terms (e.g. insanity, incapacity), but has recently been reclaimed for the broader social, cultural, even liberatory approaches to medicalized experience, especially by people treated involuntarily.

\section{Mad Pride}

An international movement of psychiatric consumer/survivors/ex-patients/mental health service users who self-identify as proud of their Mad-identity. The movement originated as Psychiatric Survivor Pride in Toronto, Canada, in 1993.

\section{Positivism:}

Positivism is based upon the following five assumptions; 
1. An ontological assumption of a single, tangible reality "out there" that can be broken apart in to pieces and capable of being studied independently; the whole is simply the sum of the parts

2. An epistemological assumption about the possibility of separation of the observer from the observed- the knower of the known.

3. An assumption of the temporal and contextual independence of observations so that what is true at one time and place may, under appropriate circumstances (such as sampling) also be true at another time and place.

4. An assumption of linear causality; there are no effects without causes and no causes without effects.

5. An axiological assumption of value freedom, that is, that the methodology guarantees that the results of an enquiry are essentially free from influence of any value system or bias.

\section{Psychocentrism:}

A concept encompassing 10 characteristics (which may or may not operate simultaneously);

1. reductionism: reducing the complexity of human experience and problems to simplistic explanations, usually by advancing the modernist view of the self-contained body-mind model;

2. determinism: claiming that human conduct and experience are determined by their “natural” bodily make-up (genetics, hormones, neurochemical, etc.); 
3. essentialism: the view that humans are essential categorical or personality types; that groups of individuals possess an innate characteristic or essence that is permanent, unalterable, stable, static, etc.;

4. presentism or ahistoricism: historical amnesia or the analytical disregard for history and its role in constituting our present understandings of our selves individually and collectively;

5. naturalism: viewing humans as natural rather than social or socially located, shaped, and produced;

6. ethnocentrism: the assumption that one's cultural practices and beliefs are normal and thus superior than other cultural practices and ways of being in the world;

7. double-standards: a set of principles unequally applied to two or more different groups. An example is the gendered double standard of sexuality where women are cast negatively while men are represented positively for the same sexual conduct; 8. victim-blaming: holding individuals and groups responsible for their own fates or negative outcomes, including their experience of mental and emotional distress or traumatic life experiences, usually by placing themselves in high risk situations; 9. positivism: using the prestige and veneer of science to construct mental illness as analogous to the same physical markers found in physical illness;

10. pathological individualism: the modern master status of the person defined in terms of ab/normalization and/or self-categorization and/or expert classification.

\section{Whiteness:}

A socially constructed category that is normalized within a system of privilege so that it is taken for granted by those who benefit from it. It is a location of structural advantage, of race 
privilege. It is also a standpoint, a place from which White people look at ourselves, at others, and at society. Lastly, "whiteness" refers to a set of cultural practices that are usually unmarked and unnamed. 


\section{GLOSSARY REFERENCES}

Applebaum, B. (2010). Introduction. In Being white, being good: White complicity, white moral responsibility, and social justice pedagogy (p. 9). United Kingdom: Lexington Books.

Lincoln, Y. S., \& Guba, E. G. (1985). Naturalistic inquiry. Sage Publications, 28.

Menzies, R., LeFrancois, B. A., \& Reaume, G. (2013). Glossary. In B. Lefrancois, R. Menzies, \& G. Reaume (Eds.), Mad Matters: A Critical Reader in Canadian Mad Studies (pp. 334340). Toronto: Canadian Scholars’ Press.

Rimke, H. (2016). Mental and emotional distress as a social justice issue: Beyond psychocentrism. Studies in Social Justice, 10(1), 4-17. 